ISSN 1991- 8690

Website: http://jsci.utq.edu.iq
الترقيم الدولي . 1991 - 199

Email: utjsci@utq.edu.iq

\title{
تأثير بعض العناصر الثقيلة في قيم الامتصاصية لمزارع الطحلب الأخضر
}

\section{Scenedesmus dimorphus}

دنيا باهل جدعان

قسم علوم الحياة ـ كلية التربية - جامعة القادسية

\section{الخلاصة}

تضمنت الدراسة بيان أثز بعض العناصر الثقيلة (الرصاص ، الكادميوم ، النحاس ، الخارصين) وسمّيتها بصورة منفردة في نمو الطحلب الأخضر Scenedesmus dimorphus وذلك بالاعتماد على قيم الامتصاصية في تقدير كتلة الطحلب الحية، ومنها تمّ حساب معدلات النمو وزمن التضـاعف عند تعريض الطحلب إلى هذه العناصر ـ كذلك تمّ حساب التركيز المتوسط الفتّال 50 EC لكل واحد من هذه العناصر الأربعة.استعملت التزاكيز

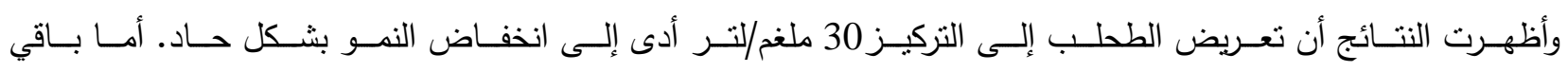
التراكيز 1 ( ) ملغم/لنز فقد انخفض فيها النمو أيضا وبشكل تدريجي. أما الكادميوم فبعد معاملة الطحلب بالتزاكيز 0.5, 0.1, 0.05 ملغ//لتز منه، انخفض عدد الخلايا في المعاملات(0.5,0.1,0.05) ملغم/لتر ، ولكن الانخفاض كان أكثر وضوحا عند استعمال التركيز 1 ملغم/لترمن الكادميوم. أما النحاس فقد استعملت التراكيز (2,1.5,1,0.5) ملغ/لتر ، وأظهرت الننائج انخفاض النمو، إلا أن التركيز 2 ملغم/لتز من النحاس كان له تأثير أكبر في خفض النمو. كما أن استعمال الخارصين بالتراكيز (3,2,1,0.7) ملغم/تنر سبّب انخفاضـا في النمو، إلا أن التركيز 3 ملغم/لتر كان لـه أثر في انخفاض النمو بشكل واضح.وأوضحت النتائج أن التأثير السمّي للكادميوم أعلى من الخارصين والنحاس والرصاص وذلك بدلالة التركيز المتوسط الفعّال الذي بلغ (6.8,0.35,0.396,0.23) ملغم/لتز بعد معاملة الطحلب الددروس بالعناصر : الرصاص، الكاديوم، النحاس،

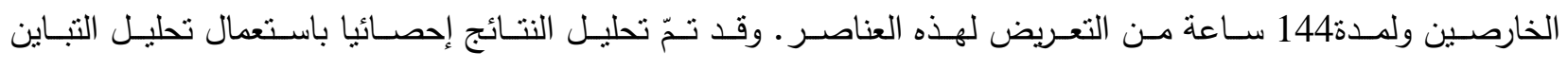
(LSD) The Least Significant Difference. واختبرت الفروق بين المعاملات بتقدير أقل فرق معنوي.(ANOVA) عند مستوى معنوية 0 .,.. 
تعدّ الطحالب من المكونات المهمة في النظم البيئية المقدمة

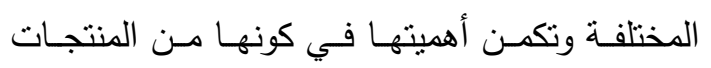
الأولية Primary producers التي تعتمد عليها بقية

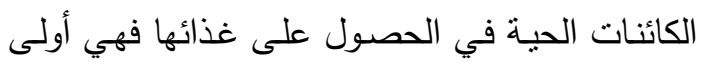

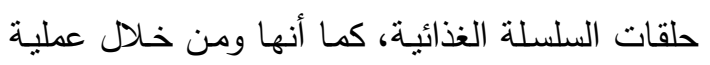
البناء الضوئي تجهز الوسط الذي تتمو فيه بكميات

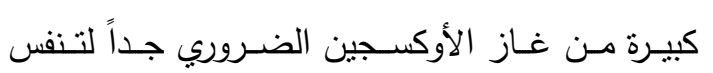

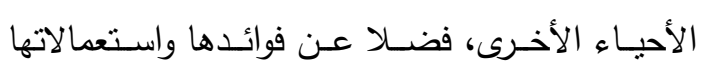

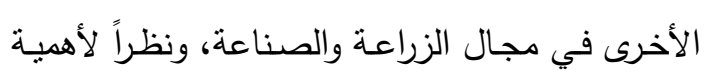
الطحالب لذا فهي مناسبة لدراسـة التأثيرات السـية ونظية الأفية

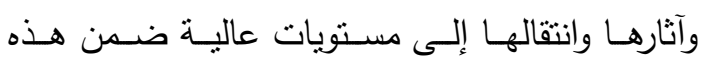

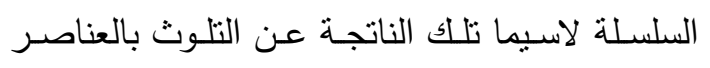
التقيلة بشكل خاص Stauber, 1995; Munda). and Hudnik, 1991) إن سمّية العناصر التقبلة تعود إلى نركيبها وخواصها الفيزيوكيميائية إذ إن هذه العناصر نوجد في الطبيعة

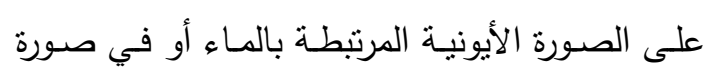

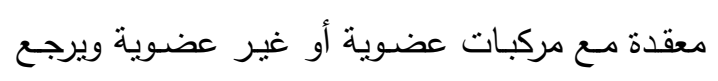
النشـاط البايولوجي لهذه العناصـر إلى سـهولة تأينها

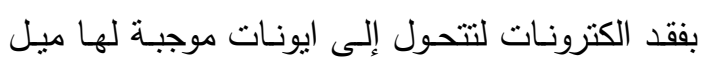

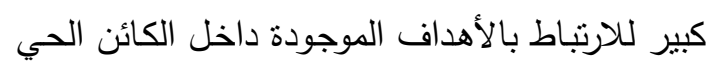

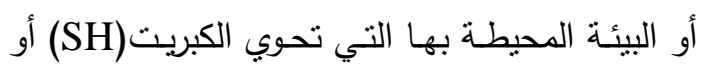

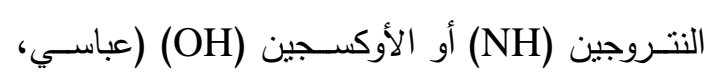
(r.. $\varepsilon$ و تعرف السّمية Toxicity بأنها التغير الإحيائي

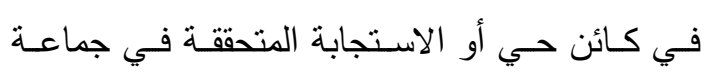
سكـانية Population والناتجــة عـن التعـرض لمـرة واحـدة أو جـرع متعاقبـة لعوامـل كيميائيـة أو فيزيائيـة

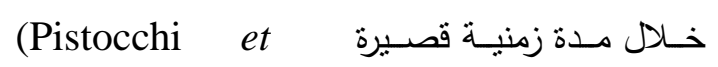
$. a l ., 1997)$ ازدادت مشكلة التلوث المائي مـع نهايـة القرن التاسـع عثر وبداية القرن العثرين نتيجة الثورة الصناعية في تهي العالم، وتعدّ هذه المشكلة من المشاكل العالمية الكبيرة والتي نتجب من سـوء التخطيط والاستعمال المضـر

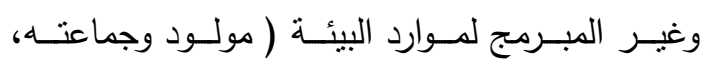
.$(199)$ ويتفق معظم الباحثني على تعريف التلوث البيئي على النى أنه التحول غير الملائم لمحيطنا كله أو معظمه نتيجة

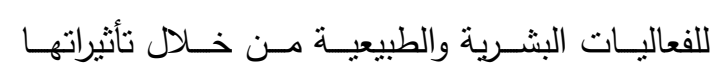
المباشـرة وغير المباشـرة للتغيرات في انسياب الطاقة ومسـتويات الإثـعاع والتركيـب الفيزيـائي والكيميـائي

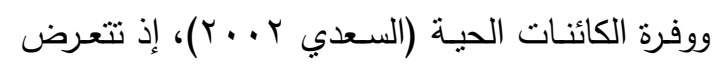

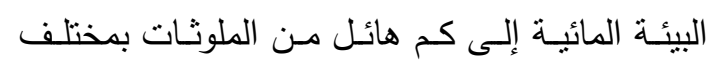
أنواعها وأنكالها سواء كانت كيميائية أو فيزيائية والتي

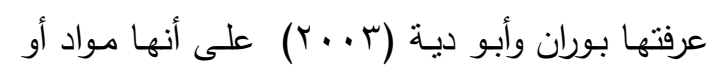

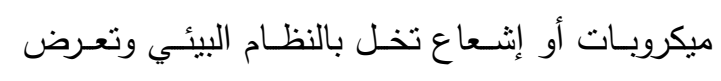

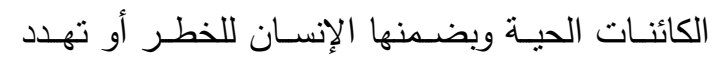
سلامة مصادره بصورة مباشرة أو غير مباشرة. يعد التلوث بالعناصر التقيلة من أخطر أنواع التلوث

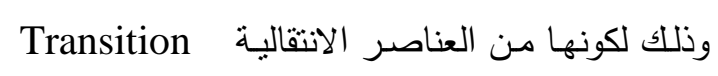
Elements معقدة ثابتــة مـع اغلـب المركبـات العضــية وغيـر

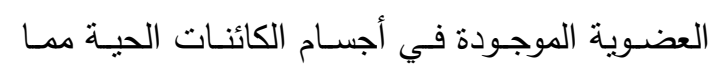

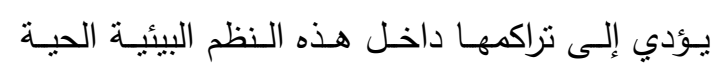

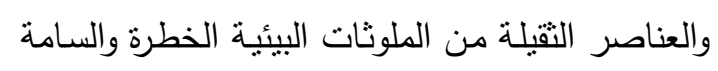

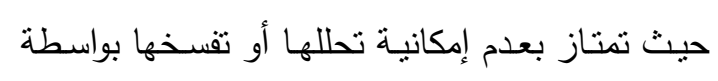
البكتريا والعمليات الطبيعية الأخرى فضـالً عن ثناتها

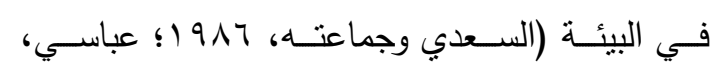
. (r... 
في حين قام محمد ( . . . ب) بدراسة التأثنرات السمية للرصاص والنحاس والكادميوم بصورة منفردة ومجتمعة في نمو الطحلب نفسه ولاحظ ازدياد معدلات التثبيط لنمو هذا الطحلب بزيادة تراكيز المعادن الثقبلة وبطول مدة التعريض. - مدوا.

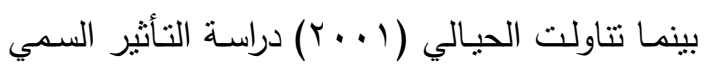
لعنصــري الرصــاص والكـــادميوم بوجـود المغـذيات

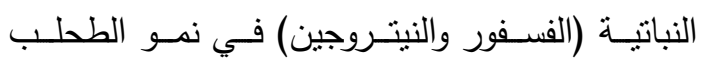

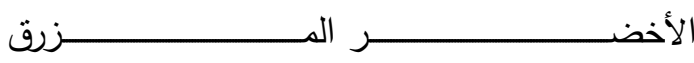
Microcystis aeruginosa

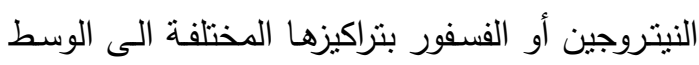
الزرعي من شـأنه أن يقلل التأثنر السـي للعناصـر التقيلة المستعطلة. أما علحم(r . . r) فقد وجد أن تركيز العناصر التقيلة

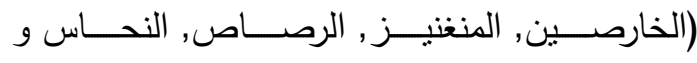
الكادميوم) في نهر الديوانية كان ضمن المواصفات

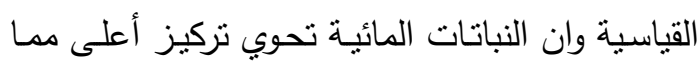
وجده في بيئتها أي أن لها القدرة على تجميع العناصر الثقبلة. بينما وجدت الصافي (0 . . †) ارتفاع تراكيز العناصر

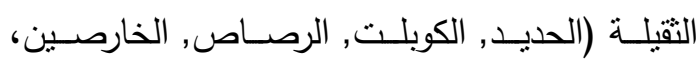
الكادميوم، النحاس) في الماء والرواسب والهائمات في قناة الخندق المرتبطة بشط العرب.

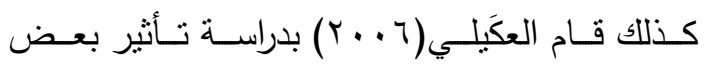

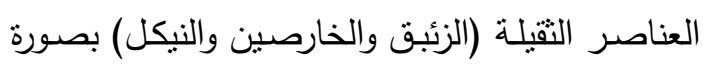
منفردة ومجتمعـة ومبيدي الكلايفوسيت والنوكوز في ولي ولئي

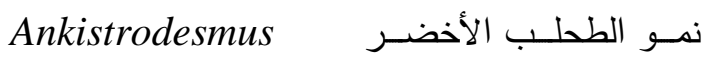

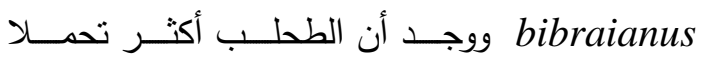
للخارصين منه للنيكل والزئبق وأن سمية مبيد النوكوز أكثر من سمية مبيد الكلايفوسيت.
وكذللك يمكن أن تعرف بأنها مقدار الضرر أو النلف الذي تسبيه مـادة كيمياويـة لكائن حي معين (العادل

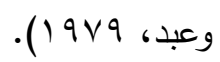

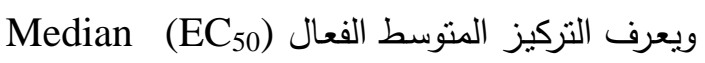
Effective Concentration الكيمياويـة التـي تعطي اسـتجابة فـي نقطـة النهايـة

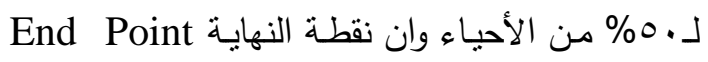
هي الأعراض التي بموجبها يحكم على وجود تأثير (Wells, سـام للمـادة الكيمياويـة فئة

أما (1998).Torres et al فقد عرفوه بأنه نركيز المادة السامة الذي يعمل على خفض نمو الجماعـة

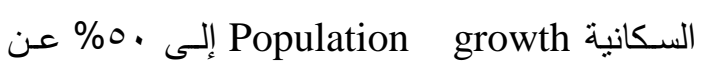
معاملة السبطرة. وقد يكون التأثير متمثناً بانخفاض

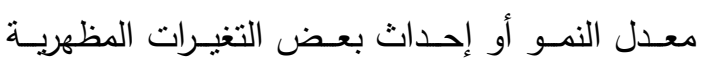
.(Crompton and Consultnt, 1998) أجريت دراسات عدة حول وجود العناصر الثقيلة في

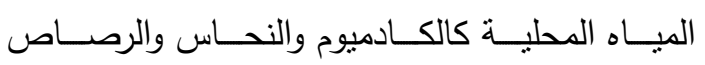

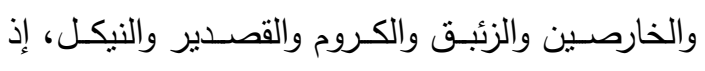
قامت الحجاج (997 ( ) بدراسة توزيع العناصر الثقيلة في شـط العرب وقنـاتي العشـار والخندق وذلك مـن

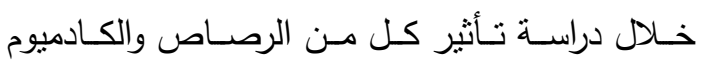

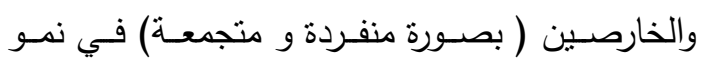

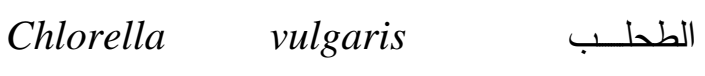
والطحلب Oscillatoria amoena إذ لاحظت أن

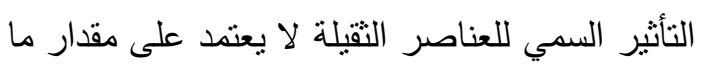

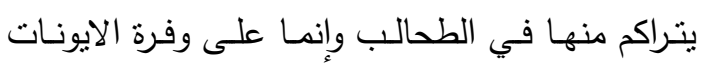

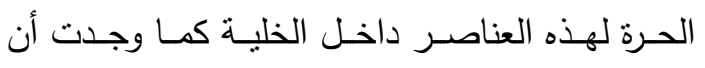
ظهور حالات التأثير التضـادي أو التآزري عند دمـج عنصرين أو أكثر تعتمد على نوع الطحلب والعنصر والتركيز المستعمل. 
(al., 1999 وكما موضح في الجدول (l) في تتمية الطحلب S. dimorphus وحضر الوسط بشكل Stocka solutions محاليـل خزينـة (احتياطيـة) عقــت جميـع المحاليـل الخزبنــة بوســاطة جهــاز المؤصدة Autoclave عند درجة حرارة اب ا درجة مئوية وضغط 0 , جو لمدة · r دقيقة وتركت لتبرد،

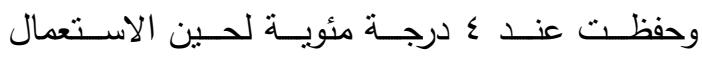

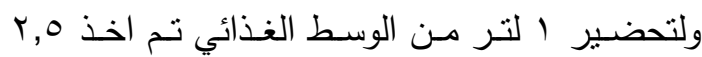

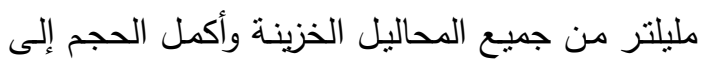
ا لتز بوساطة الماء المقطر .
وهـدفت هـذه الدراسـة إلـى تحديــ التركيـز المتوســـ

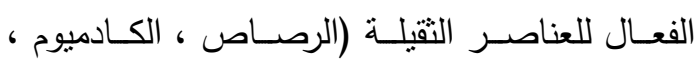

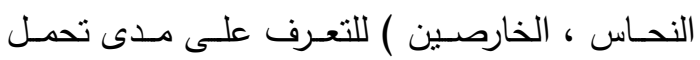

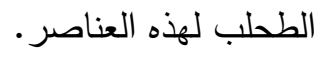
المواد وطرائق العمل

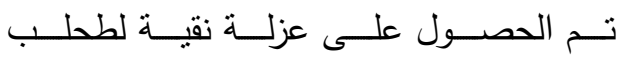
Scenedesmus dimorphus الوراثية والتقنيات الإحيائية- الدراسات العليا- جامعة مناته

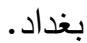

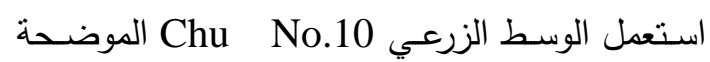
مكوناته من قبل Chu- 1942 المحور Kassim et

جدول( (1) مكونات الوسط الغذائي (Chu No - 10) المحور المستعمل في زراعة وتتمية الطحلب Scenedesmus dimophus

\begin{tabular}{|c|c|c|}
\hline رقمم1لميطول 1لاعتيا طيم. & 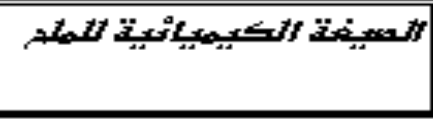 & 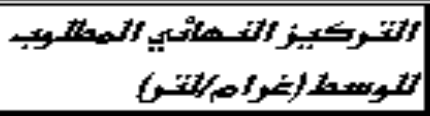 \\
\hline Stocka 1 & $\mathrm{MgSO} \cdot 7 \mathrm{H}_{2} \mathrm{O}$ & 10 \\
\hline Stocka 2 & $\mathrm{~K}_{2} \mathrm{Hp} \mathrm{O}_{4}$ & 4 \\
\hline Stocka 3 & $\begin{array}{c}\mathrm{NaNO}_{3} \\
\mathrm{CaCl}_{2}\end{array}$ & $\begin{array}{c}8 \\
16\end{array}$ \\
\hline Stocka 4 & $\mathrm{FeCl}_{3}$ & 0.32 \\
\hline Stocka 5 & $\mathrm{EDT} \mathrm{A}_{2}-\mathrm{Na}_{2}$ & 4 \\
\hline Stocka 6 & $\mathrm{NaC1}$ & 30 \\
\hline Stocka 7 & $\mathrm{Na}_{2} \mathrm{Co}_{3}$ & 8 \\
\hline Stocka 8 & $\begin{array}{c}\mathrm{MnCl} 1_{2} \cdot 4 \mathrm{H}_{2} \bigcirc \\
\left(\mathrm{NH}_{4}\right)_{6} \mathrm{Mo}_{7} \bigcirc_{24} \cdot 4 \mathrm{H}_{2} \odot \\
\mathrm{ZnS}_{4} \cdot 7 \mathrm{H}_{2} \bigcirc \\
\mathrm{CuSo}_{4} \cdot 5 \mathrm{H}_{2} \bigcirc \\
\mathrm{CoCl}_{2} \cdot 6 \mathrm{H}_{2} \bigcirc \\
\mathrm{H}_{3} \mathrm{~B} \bigcirc_{3}\end{array}$ & $\begin{array}{c}0.02 \\
0.28 \\
0.224 \\
0.08 \\
0.004 \\
0.288\end{array}$ \\
\hline Stocka 9 & $\mathrm{Na}_{2} \mathrm{Sio}_{3}$ & 10 \\
\hline
\end{tabular}

CuSo 4 . 25 $\mathrm{ZnsO}_{4}$. $7 \mathrm{H}_{2} \mathrm{O}$

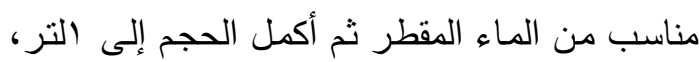
بعدها تم تعقيم كل محلول بوساطة جهاز المؤصدة

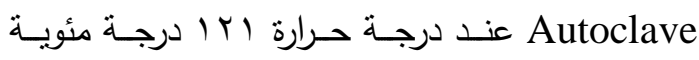
وضغط
حضرت العناصـر التقبلـة على شكل محاليل خزينـة Stocka Solutions استعملت في تحضير التخافيف المناسبة حسب كل تجربة .

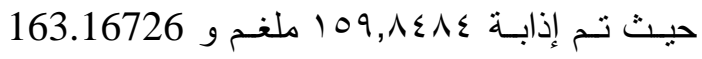
ملغم و هل 
ردهـة مـن ردهتـي شـريحة العـدّ، ثـم وضـع غطـاء

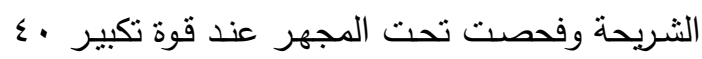

Transcet باستعمال طريقة القطاع المستعرض و X

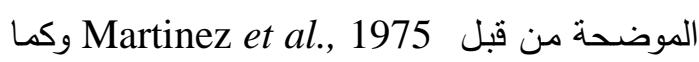
يلي :حجم النمـوذج في القطـاع الواحــ (ملـمّم) = طـول

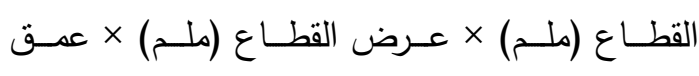
الثريحة (ملم)

عدد القطاعات في واحد مليلترمن النموذج= . . . 1. (ملمَّ) - حجم النموذج في القطاع الواحد (ملمَّ)

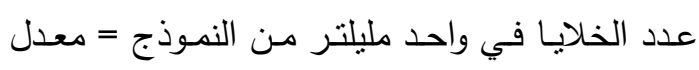

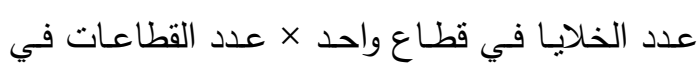

$$
\text { واحد مليلتر من النموذج. }
$$

(Nyholm, وحسب معدل التثبيط كنسبة مئويـة منودية (1985 بتطبيق المعادلة:-

Inhibition\%=1-XT/XE*100

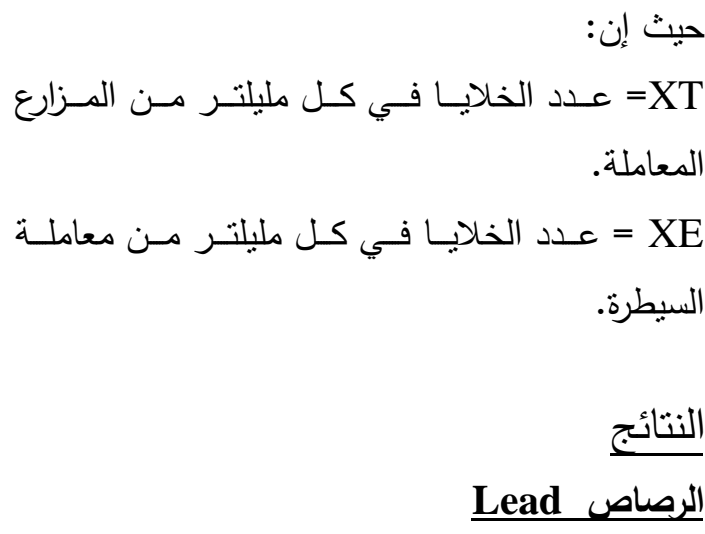

عند تعريض الطحلب المدروس إلى التراكيز (10,

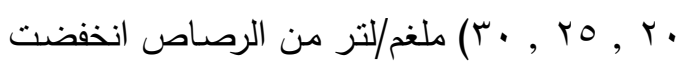

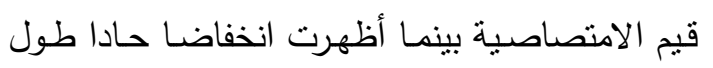

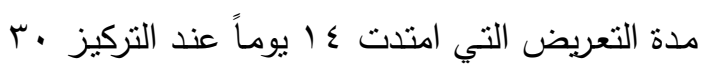

$$
\text { ملغم / لتر (الثكل ()). }
$$

أما معدلات النمو فقد انخفضت هي النّل الأخرى مـع

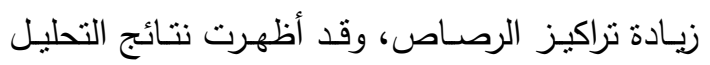
الإحصـائي وجـود فـروق معنويــة (P<0.05) بــين
عند درجة ؛ درجة مئوية في الثناجة لحين الاستعمال وتم تقدير الكتلة الحية في حالة وجود وعدم وجود

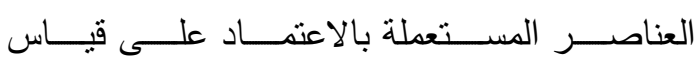

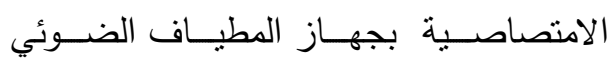

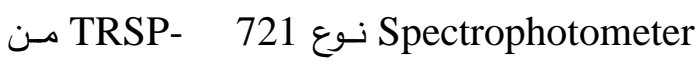
TRIUP INTERNATIONAL CORP. إنتاج

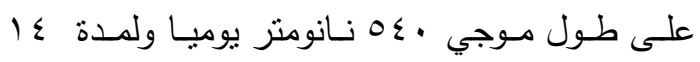
يومـاً ولجميع المعـاملات للتعـرف على كثافـة خلايـا الطحلب المدروس. تم تصفير الجهاز على الوسط ئه الزرعي المستعمل قبل المعاملة بالطحلب Tam) .and Wang, 1989) أما بالنسبة لمعدل النمو Growth rate التضـاعف Doubling time (G) فقد تم حسـابها Reynolds (1984)

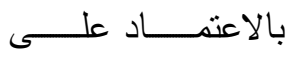
وحسب المعادلة الآتية: $\mu=I_{n}\left(X_{1} / X_{o}\right) / t$

$$
\text { : حيبث إن }
$$
= $=\mu$ $\cdot, 79 \Gamma=I_{n 2}$ X قيم الامتصاصية في بداية التجربة (نانومتر). X t أمسا زمـن التضـاعف (G) فتم الحصـول عليـه من

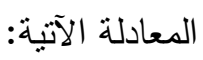
$\mathrm{G}=\mathrm{I}_{\mathrm{n} 2} / \mu$

$$
\begin{aligned}
& \text { حيث إن : } \\
& \text { G= زمن التضاعف } \\
& \text { = }=\mu
\end{aligned}
$$

وتــم حســاب عــدد الخلايــا باســتعمال شــريحة الهيماسـايتوميتز Heamacytometer المستعملة في حسـاب عدد خلايـا كريات الدم البيض وذللك بوضـع حجم معين من العينة بعد رجها جيداً على سطح كل 
التركيز (1) ملغم/لتر مقارنة بالتراكيز الأخرى خلال

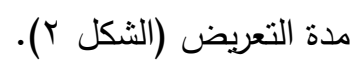
أما معدلات النمو فقد انخفضت هي الأخرى مـع ازديـاد زمـن التضـاعف للطحلب، وأوضـــت نتـائج التحليـل الإحصــائي وجـود فروقـات معنويــة بـين

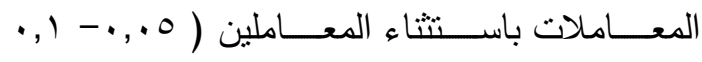
ملغم/لتر) حيث لم يظهر اختلاف معنوي بينها في

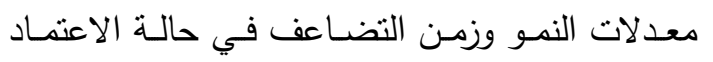
على عدد الخلايا وقيم الامتصاصية (جدول r). جدول (r ) : معدل النمو وزمن التضاعف بدلالة قيم الامتصاصية للطحلب Scenedesmus dimorphus عند تعريضه لتراكيز مختلفة من الرصاص

\begin{tabular}{|c|c|c|}
\hline 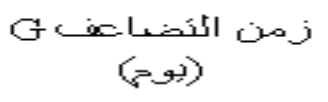 & 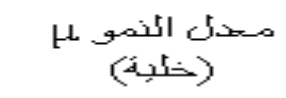 & التَركيز (ملغخ \\
\hline $0.46 \pm 5.7030$ & $0.01 \pm 0.1233$ & $\begin{array}{c}\text { Contmol } \\
\text { (O.0) }\end{array}$ \\
\hline $0.32 \pm 6.0626$ & $0.01 \pm 0.1180$ & 15 \\
\hline $1.01 \pm 6.9016$ & 0.01 \pm 0.1046 & 20 \\
\hline $0.77 \pm 7.0446$ & $0.02 \pm 0.0997$ & 25 \\
\hline $1.51 \pm 11.1395$ & $0.14 \pm 0.0645$ & 30 \\
\hline 2.980 & 0.034 & LSD \%5 \\
\hline
\end{tabular}

الأرقام تشير إلى المعدل 土 الخطأ القياسي.

جدول (ץ ): معدل النمو وزمن التضاعف بدلالة قيم الامتصاصية للطحلب Scenedesmus dimorphus عند تعريضد لتراكيز مختلفة من الكادميوم

\begin{tabular}{|c|c|c|}
\hline الامتصاصية & 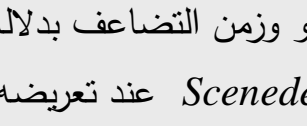 & 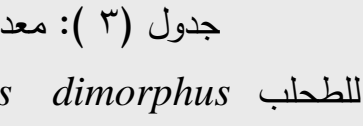 \\
\hline زمن التضضاعف) & معدل التئيو & التَركيز (ملغم /للتر) \\
\hline $0.46 \pm 5.7030$ & $0.01 \pm 0.1233$ & (0.0) Control \\
\hline $1.26 \pm 12.1486$ & $0.006 \pm 0.05842$ & 0.05 \\
\hline $7.8 \pm 18.1378$ & $0.015 \pm 0.05177$ & $\mathbf{0 . 1}$ \\
\hline $2.3 \pm 16.4861$ & $0.01 \pm 0.0439-$ & $\mathbf{0 . 5}$ \\
\hline $6.70 \pm 22.7484$ & $0.011 \pm 0.0383-$ & $\mathbf{1}$ \\
\hline 15.090 & 0.038 & LSD \%5 \\
\hline
\end{tabular}

الكادميوم Cadmium بينت نتائج الدراسة عند تعريض الطحلب إلى تراكيز

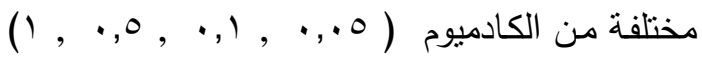
ملغم/لتر وجود انخفاض في قيم الامتصاصية ، حيث

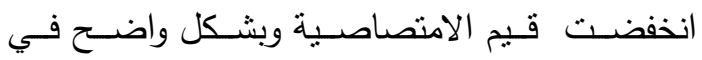

• الأرقام تشير إلى المعدل 土 الخطأ القياسي. 


\section{$\rightarrow-30 \mathrm{ppm} \rightarrow-25 \mathrm{ppm} \rightarrow-20 \mathrm{ppm} \nrightarrow-15 \mathrm{ppm} \rightarrow-$ Control}

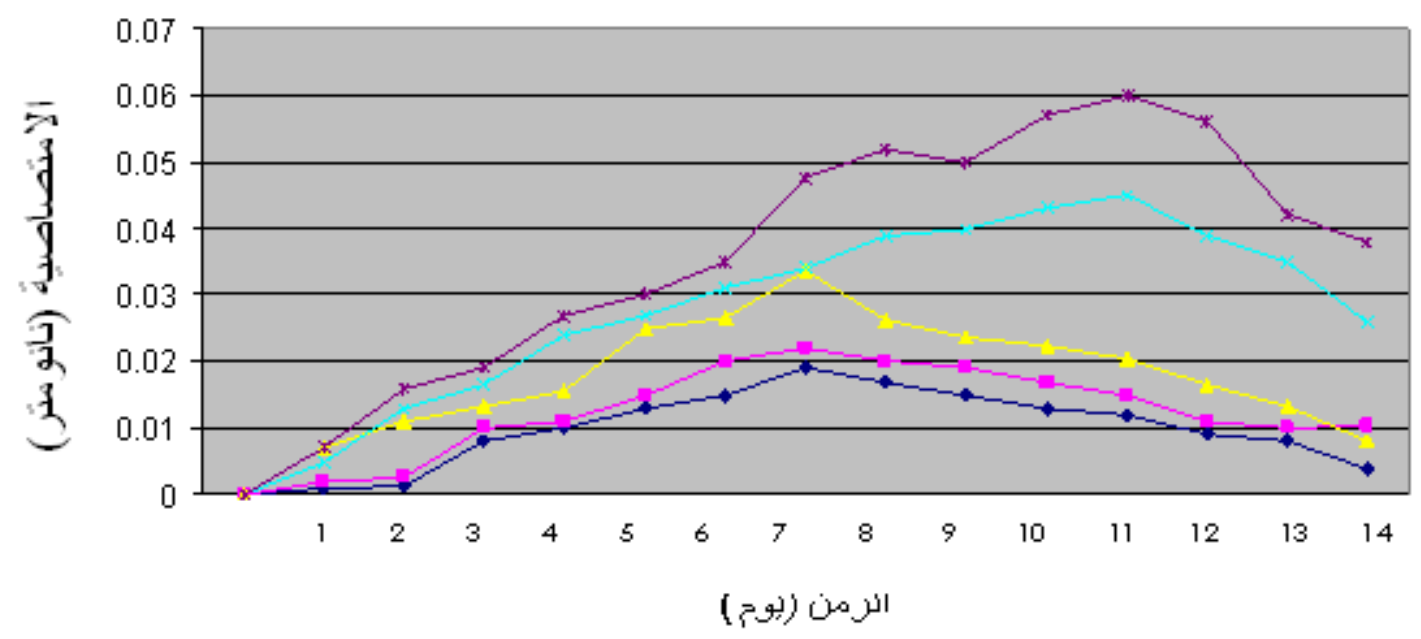

شكل( (1): منحنى النمو للطحلب Scenedesmus dimorphus بدلالة قيم الامتصاصية عند تعريضه لتراكيز مختلفة من الرصاص

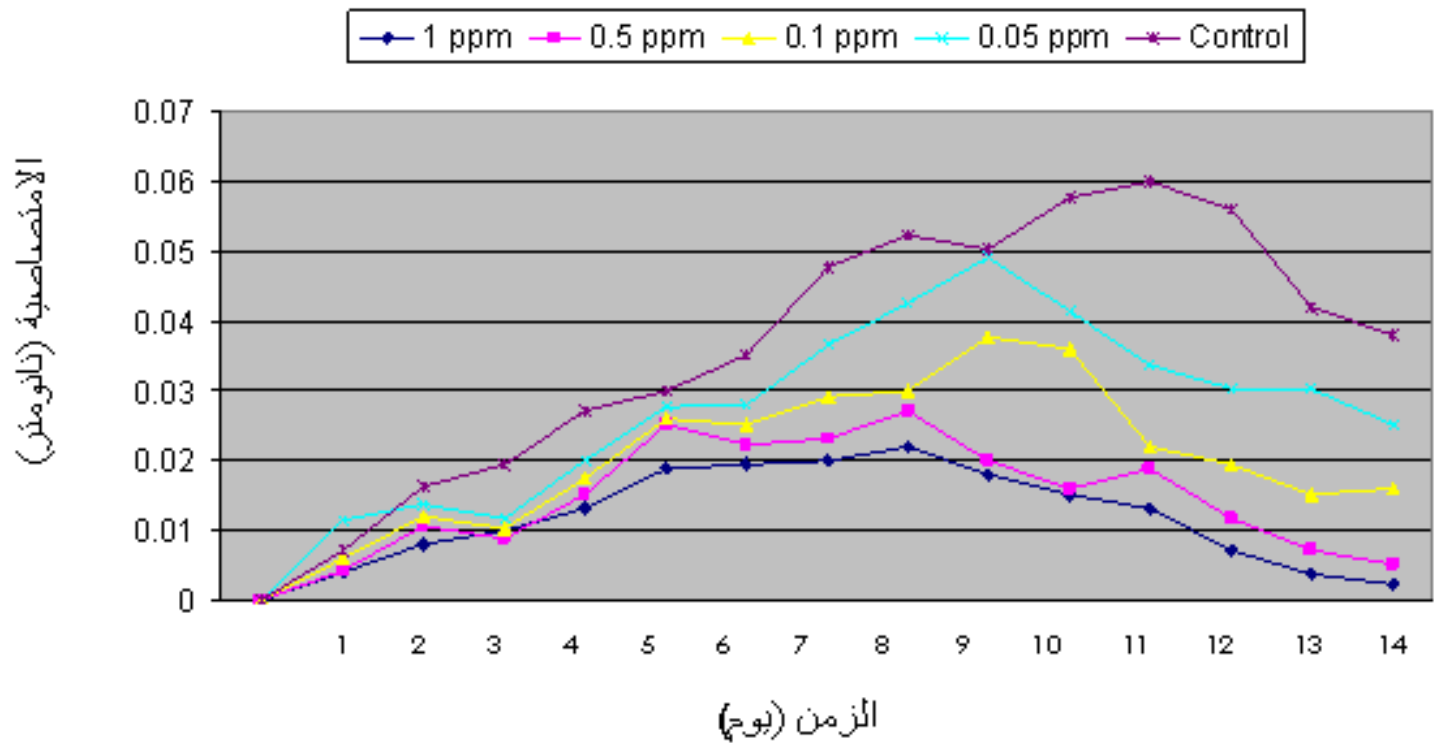

شكل(r): منحنى النمو للطحلب Scenedesmus dimorphus بدلالة قيم الامتصاصية عند تعريضه لتراكيز مختلفة من الكادميوم 
ملغم/لتز الموجود أصلاً في الوسط الغذائي الذي يمتل

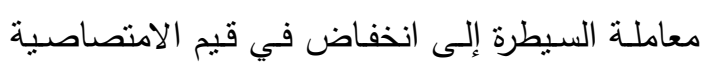

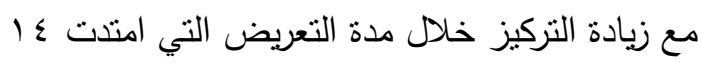

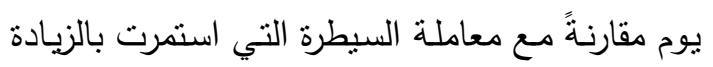
في النمو حتى نهاية التجربة وكان النقص كبيراً في

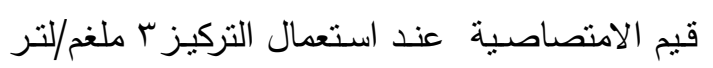

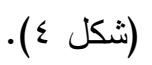
وانخفتت معدلات النمو هي الأخرى بوجود تراكيز

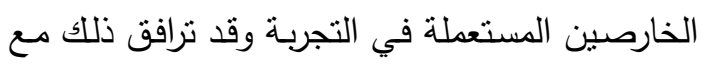

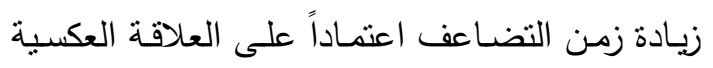

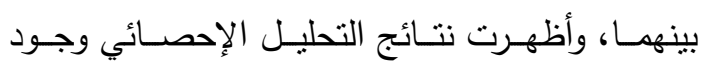
فروقات معنوية بين المعاملات (P<0.05) باستثناء

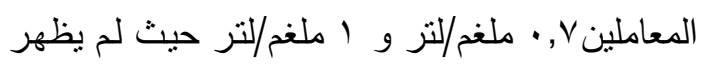

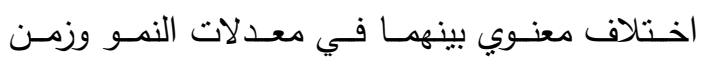

$$
\text { التضاعف (جدول 0). }
$$

\section{Copper النحاس}

عند منابعة نمو الطحلب بعد تعريضه لتراكيز مختلفة

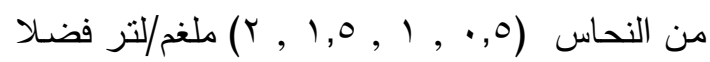

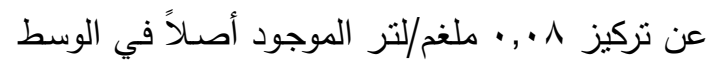

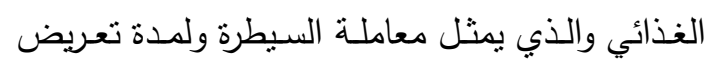

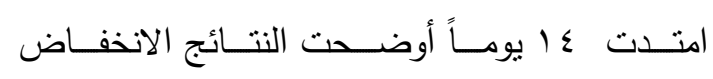

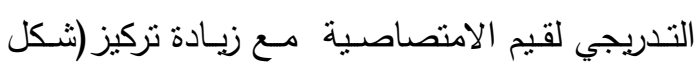

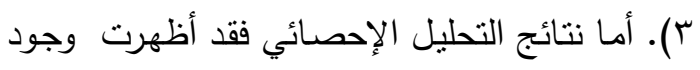
فروقات باستثناء المعاملين (0, • و 0, 1 ) ملغخ/لتر

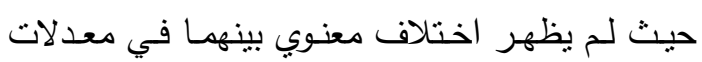

$$
\text { النمو (جدول \&). }
$$

Zinc الخارصين

Scenedesmus أنسارت نتائج تعريض الطحلب dimorphus لتراكيز مختلفة من الخارصين (r, (r) , ,

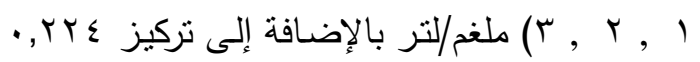

جدول (ء ): معدل النمو وزمن التضاعف بدلالة قيم الامتصاصية

\begin{tabular}{|c|c|c|}
\hline زمن التضراعف Gدمج) & معطل النمبو & التركيز (ملغغ / \\
\hline $0.46 \pm 5.703$ & $0.01 \pm 0.1233$ & (0.0) Contro1 \\
\hline $0.66 \pm 6.9620$ & $0.007 \pm 0.0996$ & 0.5 \\
\hline $1.05 \pm 6.3688$ & $0.019 \pm 0.1152$ & 1 \\
\hline $0.81 \pm 7.2862$ & $0.01 \pm 0.09748$ & 1.5 \\
\hline $1.02 \pm 9.3220$ & $0.01 \pm 0.07527$ & 2 \\
\hline 2.250 & 0.036 & LSD $\% 5$ \\
\hline
\end{tabular}
للطحلب Scenedesmus dimorphus عند تعريضه لتراكيز مختلفة من النحاس الناس

الأرقام تثير إلى المعدل \pm الخطأ القياسي. 
جدول ( 0): معدل النمو وزمن التضاعف بدلالة قيم الامتصاصية للطحلب Scenedesmus dimorphus عند تعريضه لتراكيز مختلفة من الخارصين

\begin{tabular}{|c|c|c|}
\hline زمن ألتضاعف & معل ألنميو & ألتركيز (ملنغ / \\
\hline $0.46 \pm 5.7036$ & $0.01 \pm 0.1233$ & (0.0) Contro1 \\
\hline $0.45 \pm 6.0369$ & $0.01 \pm 0.1161$ & 0.7 \\
\hline $0.80 \pm 6.0807$ & $0.03 \pm 0.1140$ & 1 \\
\hline $0.23 \pm 7.1549$ & $0.01 \pm 0.1070$ & 2 \\
\hline $0.22 \pm 7.8582$ & $0.01 \pm 0.08899$ & 3 \\
\hline 2.1000 & 0.0261 & LSD $\% 5$ \\
\hline
\end{tabular}

الأرقام تشير إلى المعدل 土 الخطأ القياسي

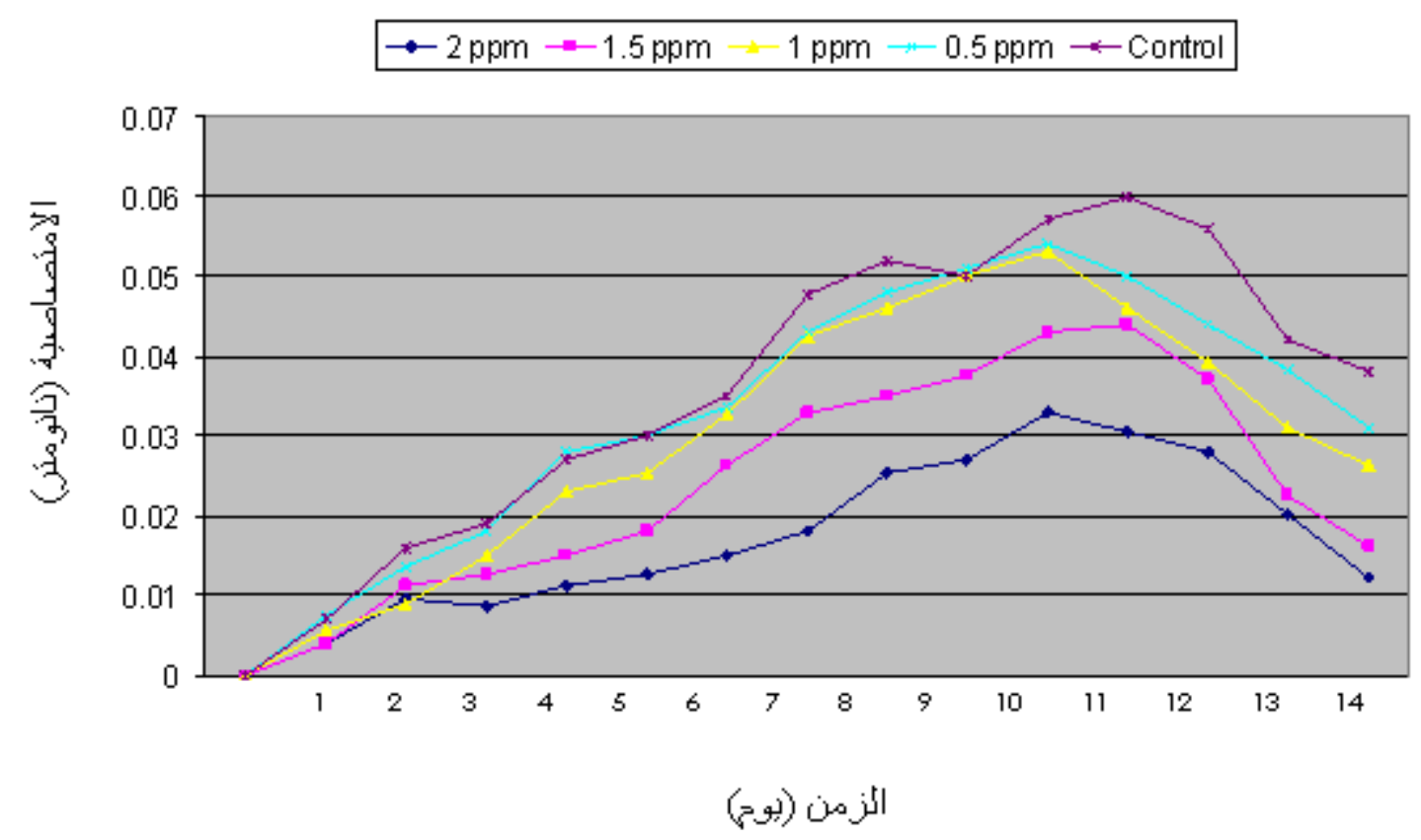

شكل(ץ): منحى النمو للطحلب Scenedesmus dimorphus بدلالة قيم الامتصاصية عند تعريضه لنراكيز مخنلفة من النحاس 


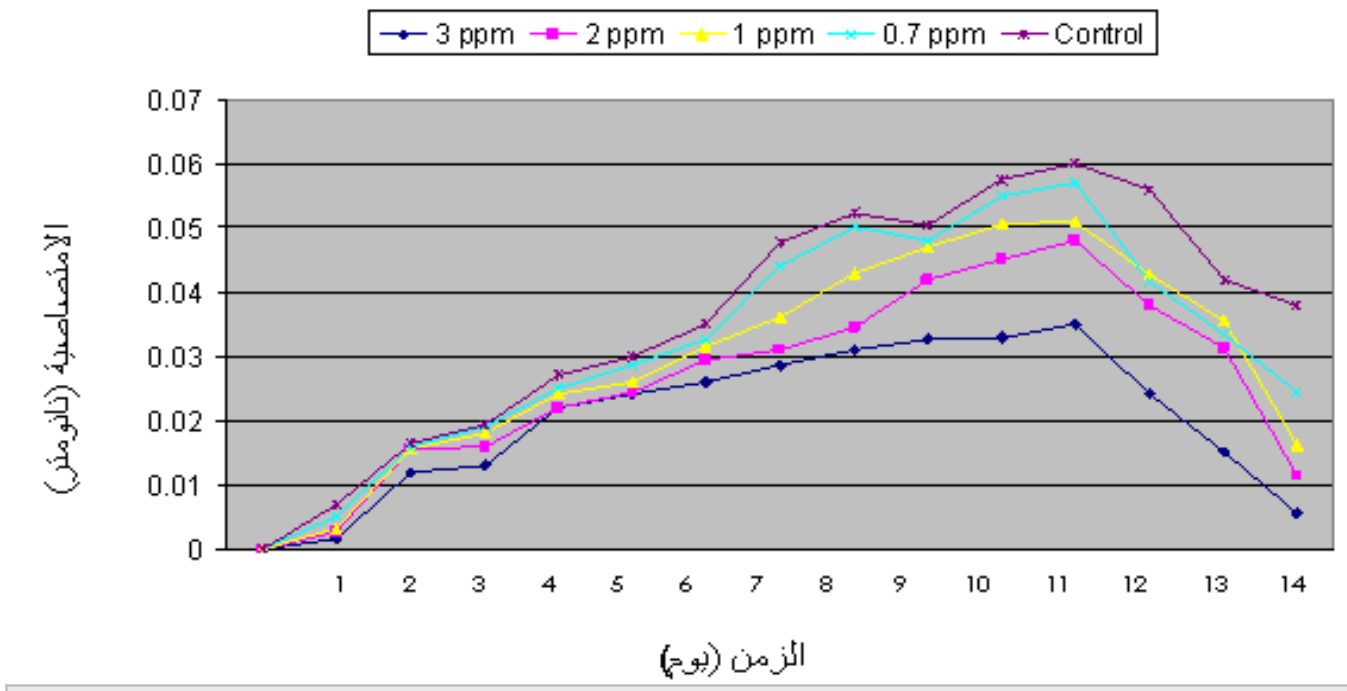

شكل(§): منحنى النمو للطحلب Scenedesmus dimorphus بدلالة قيم الامتصاصية عند تعريضه لتر اكيز مختفة من الخارصين

جدول ( T): معدلات التثبيط (\%) لنو الطحلب Scemedlessmmuss

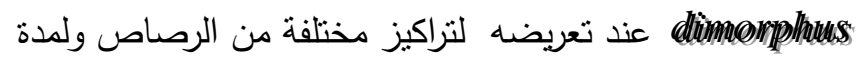

\begin{tabular}{|c|c|c|c|c|c|c|}
\hline $\begin{array}{l}144 \\
\text { سداعة }\end{array}$ & 120 سداعة & $\begin{array}{c}96 \\
\text { ساعة }\end{array}$ & سراعة & ساعنة 48 & $\begin{array}{l}24 \\
\text { سداعة }\end{array}$ & (دلفم/ لنزر) \\
\hline 0 & 0 & 0 & 0 & 0 & 0 & Control \\
\hline 88.7 & 72.0 & 73.0 & 74.6 & 60 & 60 & 15 \\
\hline 89.1 & 77.2 & 78.8 & 77.7 & 77.5 & 70 & 20 \\
\hline 89.1 & 80.1 & 80.7 & 79.3 & 82.5 & 80 & 25 \\
\hline 92.5 & 87.5 & 87.5 & 80.9 & 85 & 80 & 30 \\
\hline
\end{tabular}

معدلات التشيط (\%)

Scenedesmus تم حساب معدلات التثبيط لطحلب (ب معلات dimorphus

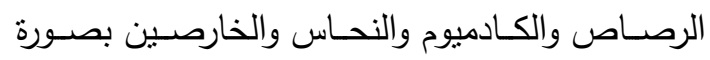

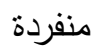

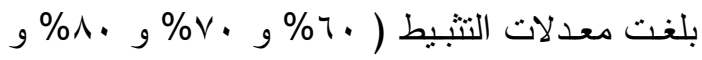

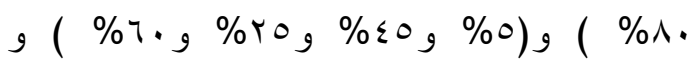

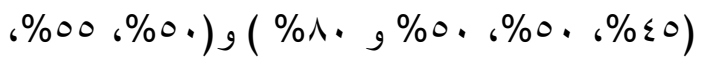

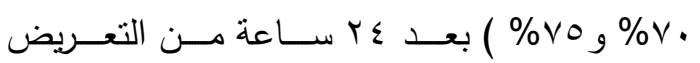

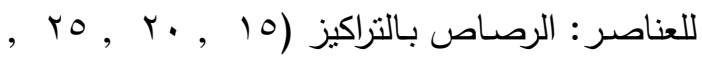
r.

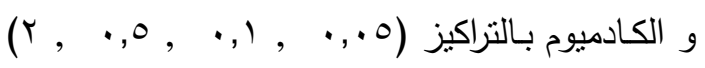

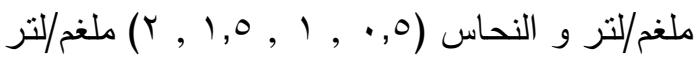

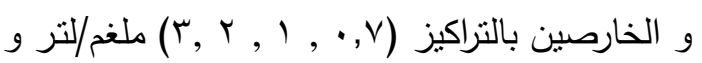

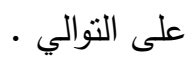
أما بعد § \& (ساعة فقد ازدادت معدلات التتبيط لجميع تراكيز العناصر المستعملة جدول (T , V, A, 9) • 
جدول (v ) ): معدلات التثبط (\%) لنمو الطحلب

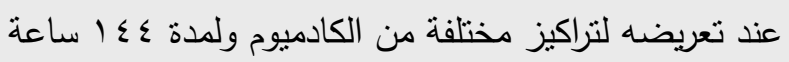

\begin{tabular}{|c|c|c|c|c|c|c|}
\hline سداعة 144 & سداعة 120 & 96 سداعة & 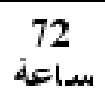 & سداعة 48 & سداعة 24 & (ملثغ/ التر) \\
\hline 0 & 0 & 0 & 0 & 0 & 0 & Control \\
\hline 71.1 & 48.5 & 37.5 & 74.6 & 72.5 & 45 & 0.5 \\
\hline 74.1 & 52.2 & 49 & 79.3 & 80 & 50 & 1 \\
\hline 79.4 & 52.9 & 49 & 82.5 & 82.5 & 50 & 1.5 \\
\hline 82.7 & 55.1 & 66.3 & 82.5 & 85 & 80 & 2 \\
\hline
\end{tabular}

جدول (1 ): معدلات التثبط (\%) لنمو الطحلب

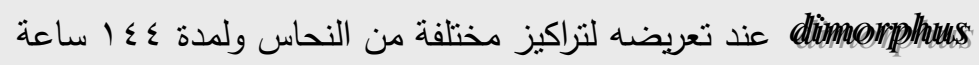

\begin{tabular}{|c|c|c|c|c|c|c|}
\hline ساعة 144 & سداعة 120 & $\begin{array}{r}96 \\
\text { ساعة }\end{array}$ & سداعة 72 & $\begin{array}{r}48 \\
4 \text { ساعة }\end{array}$ & ساعة 24 & (التزركليز \\
\hline 0 & 0 & 0 & 0 & 0 & 0 & Control \\
\hline 16.4 & 11.7 & 12.5 & 0 & 5 & 5 & 0.05 \\
\hline 24.3 & 18.3 & 12.5 & 3.1 & 12.5 & 45 & 0.1 \\
\hline 74.9 & 44.8 & 48.0 & 39.6 & 42.5 & 25 & 0.5 \\
\hline 88.3 & 83.8 & 75.9 & 77.7 & 67.5 & 60 & 1 \\
\hline
\end{tabular}

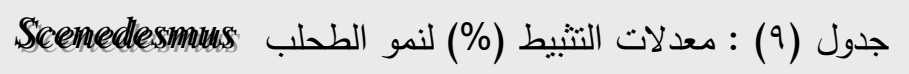

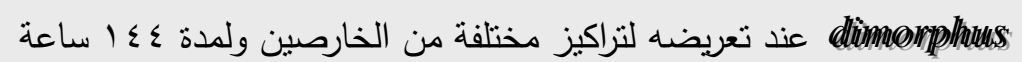

\begin{tabular}{|c|c|c|c|c|c|c|}
\hline سـاعة 144 & 120 سداعة & سداعَ 96 & سداعة 72 & سداعة 48 & ساعة 24 & (ملفغ/ التّر) \\
\hline 0 & 0 & 0 & 0 & 0 & 0 & Control \\
\hline 89.8 & 83 & 78.8 & 79.3 & 57.5 & 50 & 0.7 \\
\hline 90.2 & 87.5 & 83.6 & 77.7 & 85 & 55 & 1 \\
\hline 91.3 & 87.5 & 84.6 & 82.5 & 85 & 70 & 2 \\
\hline 93.2 & 89.7 & 85.5 & 85.7 & 85 & 75 & 3 \\
\hline
\end{tabular}

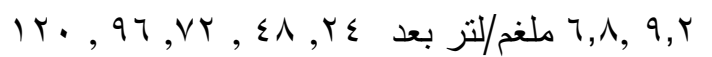

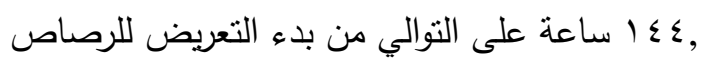
(جدول · (1)
تقدير سمّية العناصر الثقيلة تم تقدير سمّية العناصر الثقيلة في الطحلب المدروس من خـلال حسـاب التركيز المتوسط الفعال

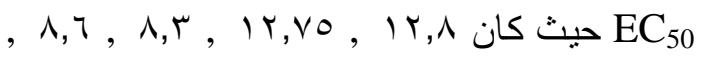


جدول(· ( ): سمّية عنصر الرصاص والتركيز المتوسط الفعال له خلال ع ـ ا ساعة في الطحلب Scenedesmus dimorphus

\begin{tabular}{|c|c|c|c|c|c|c|c|c|c|c|c|c|c|}
\hline \multicolumn{2}{|c|}{144 ساءعة } & \multicolumn{2}{|c|}{120 ساءعة } & \multicolumn{2}{|c|}{96} & \multicolumn{2}{|c|}{72} & \multicolumn{2}{|c|}{48 ساءكة } & \multicolumn{2}{|c|}{24} & \multirow{2}{*}{ 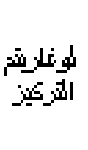 } & \multirow{2}{*}{ 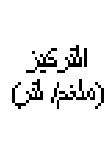 } \\
\hline 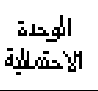 & الأنتجلبة & الانتشخلئة & الأنجنجلة & الاختشيلية & لالأنتجلابة & الاحتشعلية & الأنجنلية & الأختهَيلية & لالانتجلاية & الخاختملئة & الأنجنلبة & & \\
\hline- & - & - & - & - & - & - & - & - & - & - & - & - & الئسلِطُرة \\
\hline 6.22 & 89 & 5.58 & 72 & 5.61 & 73 & 5.67 & 75 & 5.25 & 60 & 5.25 & 60 & 1.17 & 15 \\
\hline 6.22 & 89 & 5.73 & 77 & 5.80 & 79 & 5.77 & 78 & 5.77 & 78 & 5.25 & 70 & 1.30 & 20 \\
\hline 6.22 & 89 & 5.84 & 80 & 5.87 & 81 & 5.80 & 79 & 5.95 & 83 & 5.84 & 80 & 1.39 & 25 \\
\hline 6.47 & 93 & 6.17 & 88 & 6.17 & 88 & 5.84 & 81 & 6.03 & 85 & 5.84 & 80 & 1.47 & 30 \\
\hline \multicolumn{2}{|c|}{6.8} & \multicolumn{2}{|c|}{9.2} & \multicolumn{2}{|c|}{8.6} & \multicolumn{2}{|c|}{8.3} & \multicolumn{2}{|c|}{12.755} & \multicolumn{2}{|c|}{12.8} & \multicolumn{2}{|c|}{ EC 50} \\
\hline
\end{tabular}

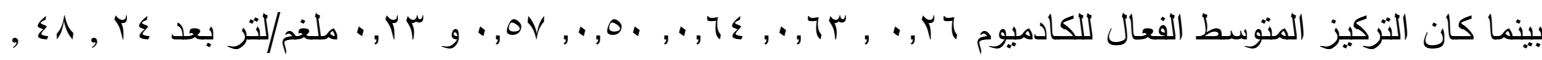

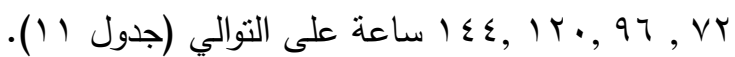

جدول(1 1 ) ): سمّية عنصر الكادميوم والتركيز المتوسط الفعال له خلال ؟ ؛ ا ساعة في الطحلب Scenedesmus dimorphus

\begin{tabular}{|c|c|c|c|c|c|c|c|c|c|c|c|c|c|}
\hline \multicolumn{2}{|c|}{144 ساءs } & \multicolumn{2}{|c|}{120 ساءكة } & \multicolumn{2}{|c|}{96 ساءعة } & \multicolumn{2}{|c|}{72} & \multicolumn{2}{|c|}{48} & \multicolumn{2}{|c|}{24 ساءة 24} & \multirow{2}{*}{ 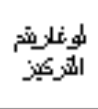 } & \multirow{2}{*}{ 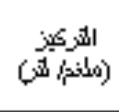 } \\
\hline الأنهايلية & 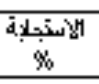 & النوخديلة & 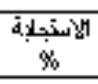 & 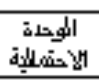 & الأنَّبلإة & 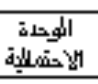 & 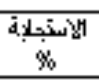 & الاختصغيلية & اللأنَّبلإة & الخاختشلئة & 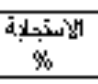 & & \\
\hline - & - & - & - & - & - & - & - & - & - & - & - & - & السلسجلُّرة \\
\hline 4.00 & 16 & 3.82 & 12 & 3.87 & 13 & - & - & 3.35 & 5 & 3.35 & 5 & $1.30-$ & 0.05 \\
\hline 4.29 & 24 & 4.08 & 18 & 3.87 & 13 & 3.11 & 3 & 3.87 & 13 & 4.87 & 45 & $1-$ & 0.1 \\
\hline 5.67 & 75 & 4.87 & 45 & 4.95 & 48 & 4.74 & 40 & 4.82 & 43 & 4.32 & 25 & $0.3-$ & 0.5 \\
\hline 6.17 & 88 & 5.99 & 84 & 5.70 & 76 & 5.77 & 78 & 5.4 & 68 & 5.25 & 60 & 0 & 1 \\
\hline \multicolumn{2}{|c|}{0.23} & \multicolumn{2}{|c|}{0.57} & \multicolumn{2}{|c|}{0.502} & \multicolumn{2}{|c|}{0.64} & \multicolumn{2}{|c|}{0.63} & \multicolumn{2}{|c|}{0.26} & \multicolumn{2}{|c|}{ EC 50} \\
\hline
\end{tabular}

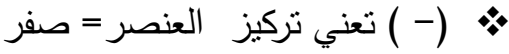

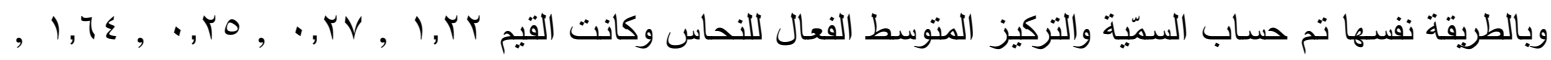

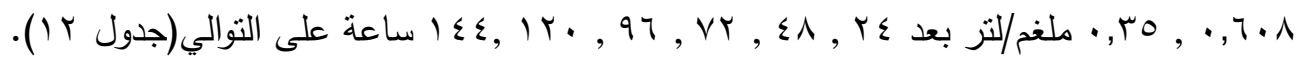


جدول(r I ): سمّية عنصر النحاس والتركيز المنوسط الفعال لله خلال ؟ ـ ا ساعة في الطحلب Scenedesmus dimorphus

\begin{tabular}{|c|c|c|c|c|c|c|c|c|c|c|c|c|c|}
\hline \multicolumn{2}{|c|}{144} & \multicolumn{2}{|c|}{120} & \multicolumn{2}{|c|}{96} & \multicolumn{2}{|c|}{ (12 72} & \multicolumn{2}{|c|}{48} & \multicolumn{2}{|c|}{24} & \multirow{2}{*}{ 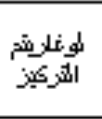 } & \multirow[b]{2}{*}{ (ملانزي) تلني) } \\
\hline 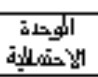 & الעن & 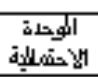 & 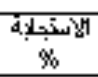 & 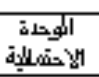 & 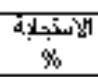 & 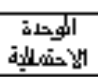 & 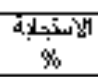 & 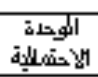 & 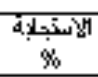 & 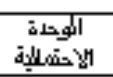 & 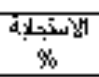 & & \\
\hline - & - & - & - & - & - & - & - & - & - & - & - & $1.09-$ & السجبطُرة، 0.08 \\
\hline 5.55 & 71 & 4.97 & 49 & 4.69 & 38 & 5.67 & 75 & 5.61 & 73 & 4.87 & 45 & $0.3-$ & 0.5 \\
\hline 5.64 & 74 & 5.05 & 52 & 4.97 & 49 & 5.80 & 79 & 5.84 & 80 & 5.00 & 50 & 0 & 1.0 \\
\hline 5.80 & 79 & 5.07 & 53 & 4.97 & 49 & 5.95 & 83 & 5.95 & 83 & 5.00 & 50 & 0.17 & 1.5 \\
\hline 5.95 & 83 & 5.12 & 55 & 5.41 & 66 & 5.95 & 83 & 6.03 & 85 & 5.84 & 80 & 0.30 & 2.0 \\
\hline \multicolumn{2}{|c|}{0.35} & \multicolumn{2}{|c|}{0.608} & \multicolumn{2}{|c|}{1.64} & \multicolumn{2}{|c|}{0.25} & \multicolumn{2}{|c|}{0.27} & \multicolumn{2}{|c|}{1.22} & \multicolumn{2}{|c|}{ EC 50} \\
\hline
\end{tabular}

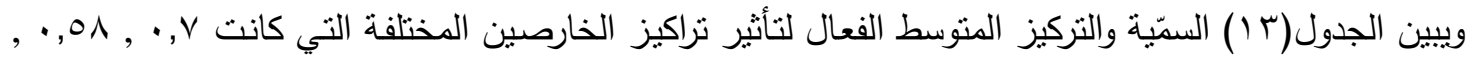

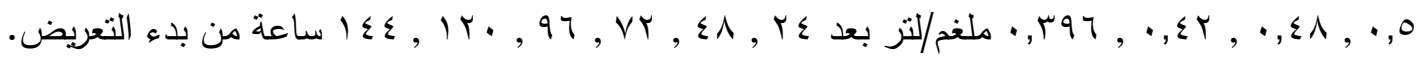

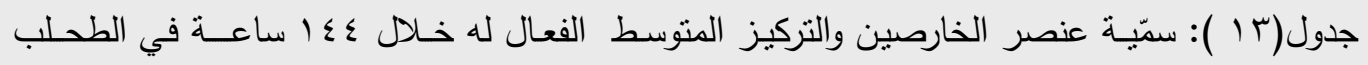
Scenedesmus dimorphus

\begin{tabular}{|c|c|c|c|c|c|c|c|c|c|c|c|c|c|}
\hline \multicolumn{2}{|c|}{144} & \multicolumn{2}{|c|}{ l 120} & \multicolumn{2}{|c|}{ إع 96 ساءة } & \multicolumn{2}{|c|}{ ( 72} & \multicolumn{2}{|c|}{ dاءs 48} & \multicolumn{2}{|c|}{ d 24} & \multirow{2}{*}{ 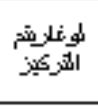 } & \multirow{2}{*}{ (ملاني) تئزي) } \\
\hline 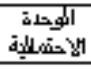 & 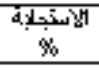 & 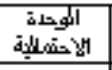 & 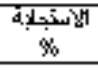 & 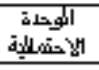 & 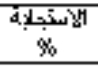 & 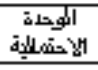 & $\frac{11}{10}$ & 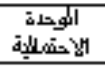 & 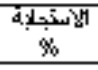 & 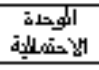 & $\frac{1}{\dot{3}}$ & & \\
\hline - & - & - & - & - & - & - & - & - & - & - & - & $0.64-$ & السجلطُّلة 0.224 \\
\hline 6.28 & 90 & 5.95 & 83 & 5.80 & 79 & 5.80 & 79 & 5.20 & 58 & 5.00 & 50 & $0.15-$ & 0.7 \\
\hline 6.28 & 90 & 6.17 & 88 & 5.99 & 84 & 5.77 & 78 & 5.03 & 85 & 5.12 & 55 & 0.00 & 1.0 \\
\hline 6.34 & 91 & 6.17 & 88 & 6.03 & 85 & 5.95 & 83 & 6.03 & 85 & 5.52 & 70 & 0.30 & 2.0 \\
\hline 6.47 & 93 & 6.28 & 90 & 6.08 & 86 & 6.08 & 86 & 6.03 & 85 & 5.67 & 75 & 0.48 & 3.0 \\
\hline \multicolumn{2}{|c|}{0.396} & \multicolumn{2}{|c|}{0.42} & \multicolumn{2}{|c|}{0.48} & \multicolumn{2}{|c|}{0.5} & \multicolumn{2}{|c|}{0.58} & \multicolumn{2}{|c|}{0.7} & \multicolumn{2}{|c|}{ EC 50} \\
\hline
\end{tabular}

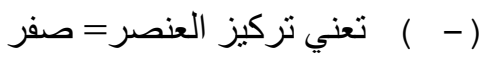


للتشــابه الكيميـائي بـين العنصــرين مدــا يجعلهمــا

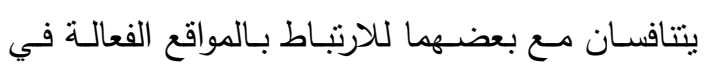

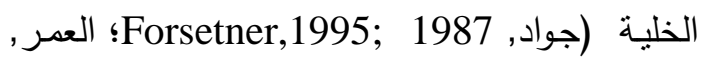
(Y. . . . الخلوي بشكل تام مما يؤدي إلى خروج السوائل من لن

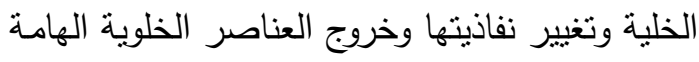
Rai et ) مثل البوتاسيوم والصوديوم والمغنيسيوم .(al., 1990

ومن خلال ملاحظة الجدول (r) يتبين انخفاض معدلات النمو وارتفاع زمن التضاعف بشكل حاد عند تعريض الطحلب المدروس إلى نركيز 1 ملغم/لتر من بندي الكـادميوم وقـــ يعـود هـذا لامـتلاك الكـادميوم مـيلاً للارتباط مع مجاميع السلفاهيدرال (SH)- التي تعنبر

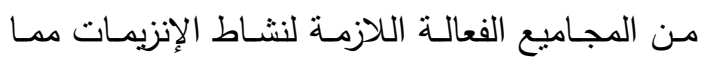
يؤدي إلى إبطال نشاطها أو يعود تأثيره لتنبيط عملية

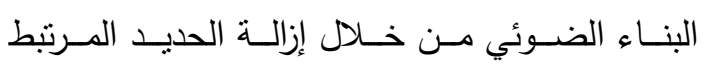

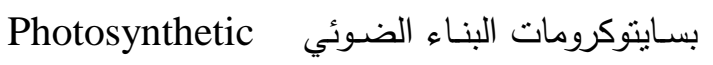
Cytochrome والمنغنيز الذي يسـهم في تفاعلات Rachlin et al., 1983; (نطلاق الأوكسجين .(Harrison and Marel, 1983 إن نتائج الدراسة الحالية تتفق مع ما توصل إليه

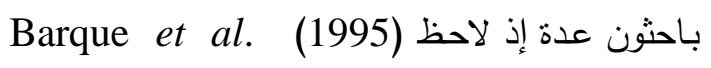

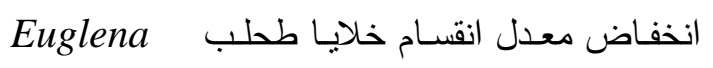
gracilis

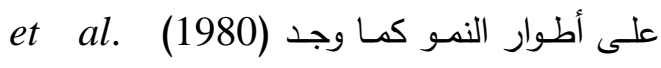
Albergoni

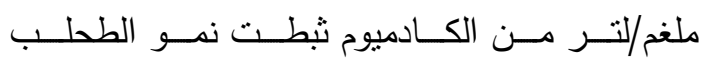
Euglena gracilis انخفاض نمو الطحلب S. dimorphus عند تعريضـه لتراكيز عالية من النحاس، فمن خلال متابعة منحنى لهن

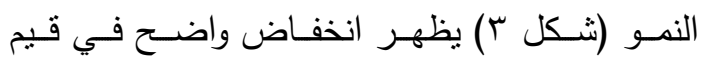

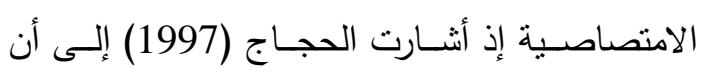

المناقشة

أنثـارت نتائج الدراسـة الحاليـة إلى انخفاض في معدل نمو الطحلب S. dimorphus عند إضـافة تراكيـز مختلفــة مـن الرصــاص (15,20,25,30) ملغم/لتر إذ لوحظ مـن متابعـة منحنى نمو الطحلب

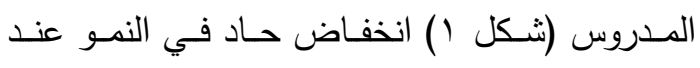
تعـريض الطحلب إلى نركيزز عـالٍ 30 ملغم/لتـردن

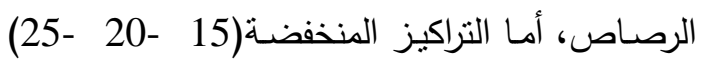

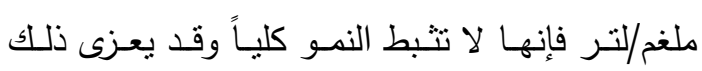
لارتباط ايونات الرصاص مع مواد أخرى داخل الخلية وتحولها إلى شكل غير فعـال كمـا أنثـار (1990) Vymazal متعدد الفوسفات داخل الخلية يجعلها غير فعالة. بينت نتائج الجدول (Y) وجود علاقة عكسية بين زيادة تراكيز الرصاص ومعدلات النمو وأخرى طردية

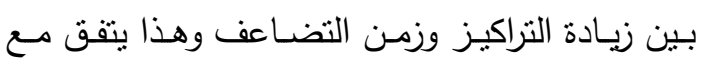
العديد من الدراسات التي أثنارت إلى دور الرصاص ونس

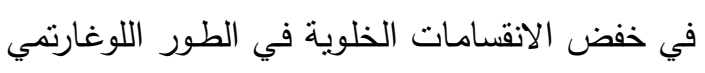
Exponential phase

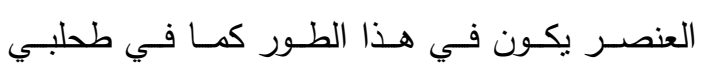
Platymonus, Chlorella Saccharophila (Jensen et al., 1982) subcordiformis يـؤثز في عمليـة البنـاء الضـوئي مـن خـلال إحداثـه

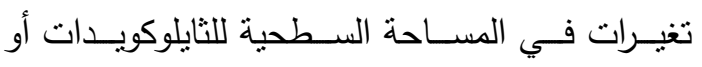
لارتباطسه بمواقـع ايضـية غيـر مخصصـة لـه ويثبط

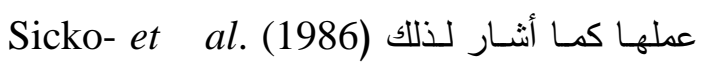
.Goad أظهرت نتائج الدراسة الحالية أن هنالك تثبيطاً في نمو الطحلبS. dimorphus قد حصل نتيجة

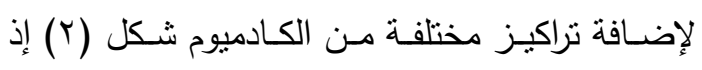
يحل الكادميوم محل الخارصين في بعض الإنزيمات ويثبط عملها مؤدياً بذلك إلى تثبيط نمو الخلايا وذلك 
إن الانخفاض الواضـح في معدلات نمو الطحلب

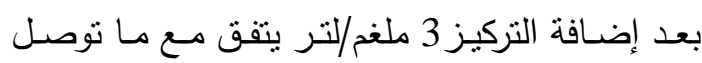
إليه Kessler (1986) و Patterson (1983)

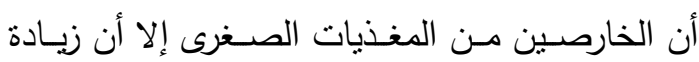
تركيزه عن حدود معينة يؤدي إلى انخفاض معدلات

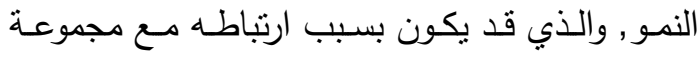

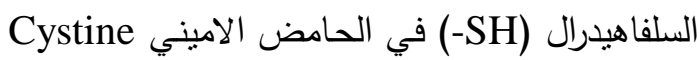

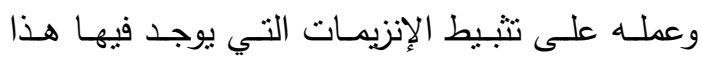
Munda and Hudnik, 1986) الحامض . (Sunda, 1990; معدلات التثبط والتركيز المتوسط الفعال تـم حسـاب معدلات التثبـيط وتقدير السـمّية مـن خـلال حسـاب التركيز المتوسط الفعـال عند تعريض مليض الطحلب Scenedesmus dimorphus إلى تراكيز مختلفـة من العناصـر الثقيلة (الرصـاص، الكادميوم،

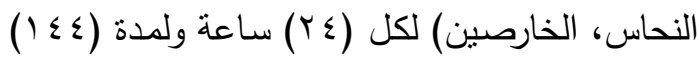
سـاعة حيث أظهرت النتائج زيـادة معدلات التثبط بزيادة تراكيز العناصـر التقيلة المستعملة في التجربـة الحالية وبطول مدة التعريض ورافق ذلك انخفاض في تراض قيم EC50 المستخرجة مما يدل على التأثير السّمي

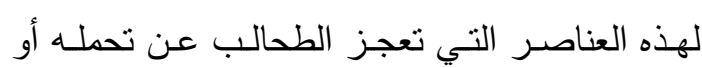
مقاومته، إذ أشـار (1993) .Saenz el al a إلى أن

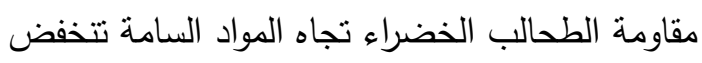
بزيادة التراكيز وطول مدة التعريض • لوحظ عند حساب قيم EC

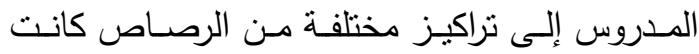

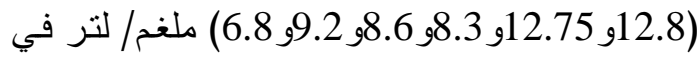
الدراسة الحالية (جدول • ()، وهذا يتفق مع ما توصل إلبه قاسم وجماعته (2000) إذ وجدوا أن قيم EC Scenedesmu sp. تنخفض عند تعريض طحلب إلى تراكيز مختلفة من الرصاص لمدة 96 ساعة , في حين وجد(1982) .Jensen el al زيادة قيم
النحاس بتراكيزه المنخفضة (20.25) لـه أهمية كبيرة في نمو الطحلب Oscillatoria amaena إلا أن التراكيـز العاليــة (>0.5) تسـبـ تتبــبط العمليــات الايضية كالبناء الضـوئي والتنفس وذلك عن طريـق تثبيط فعالية إنزيم Cytochrom Oxidase المسؤول عن نقل الاككترونـات في المايتوكونـدريا وتثبيط الـ Plastocyanin

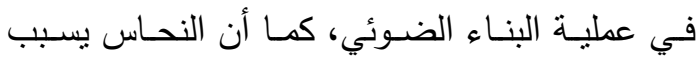
تحطيم غشاء البلاستبدات والـ DNA ويثبط الانقسام الخلوي ( Rijstenbil et al., 1994$)$

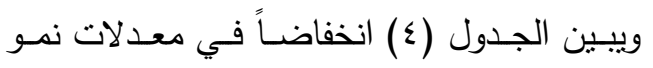
الطحلب مع زيادة تراكيز النحاس ويرافق ذلك ارتفاع

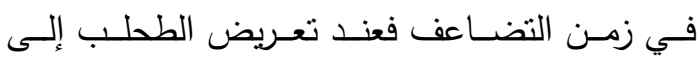
التراكيز الواطئة (0.5-1.5-1.5) ملغم/لتز في الدراسة فان التأثنر السمي لهذه التراكيز واطئ مقارنة بالتراكيز العالية (r)ملغم/لتر ، وهذا قد يعود لاحتياج الطحلب إلى هذا العنصر لأداء الفعاليات الايضية أو لإنتاج

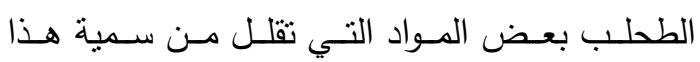
Albergoni et al., العنصر فقد ذكر (1980) أن للطحالب القدرة على إنتاج روابـط عضـوية لهـا

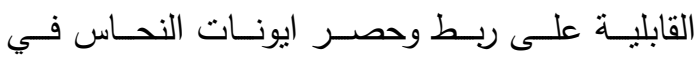
السـايتوبلازم ومـن ثمّ تقليـل سـيته ومنهـا البروتينـات السـكرية Glycoprotins والكربوهيـدرات والمركبـات

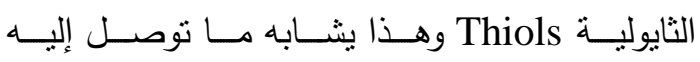
Torres et al., (1998) - Cylindrothica fusiformis يتبين من (الجدوله) و (الثكل ع) انخفاض في

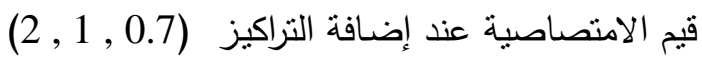

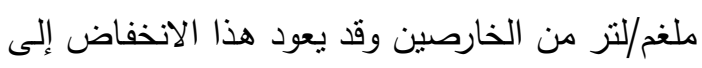

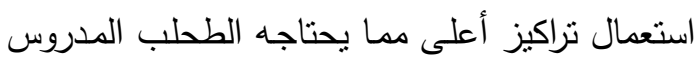
للنمو بشكل طبيعي. 
يتفق مـع ما توصل إليه محمد (2000) في دراسته على الطحلب .Scenedesmus sp وعند تعريضه للنحاس وبعد 96 ساعة في حين أظهرت دراسة أخرى ولطري على الطحلب Navicula incerta ارتقاع قيمـة Rachlin et ( بعد تعرضه للنحاس 96 ساعة EC .(al., 1983 إن سبب انخفاض قيمة EC50 بعد (24) ساعة من تعريض الطحلب المدروس إلى عنصر النحاس

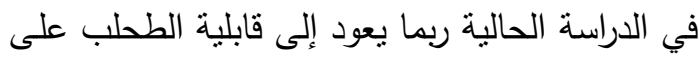

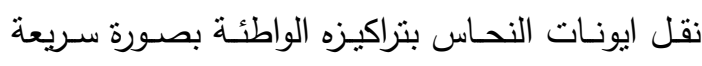

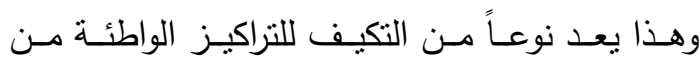

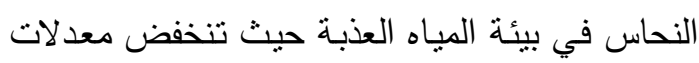

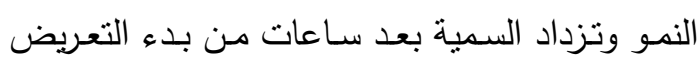
بسبب تراكم عنصر النحاس بسرعة كبيرة وبتراكيزه

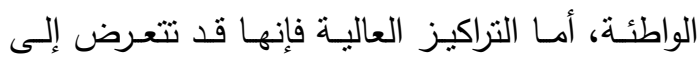

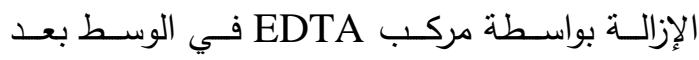

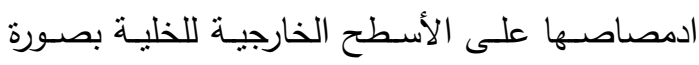
أكثر من دخولها إلى داخل الخلية وبذللك يقل تراكمها

داخل الخلية(Knaur et al., 1997) .

توضسح النتائج في الجدول(13) أن قيم عند تعريض الطحلب للخارصين في الدراسة الحالية كانت منخفضة ومنباينة , 0.396, 0.42,0.48 0.5, 0.58, 0.7 ملغم/لتر ، وان هذه النتائج تنوافق مع ما توصل إليه (1990) Wong and Chan

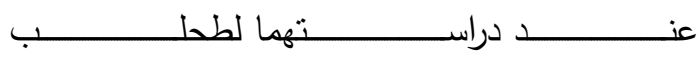
Ankistrodesmus falcatus مشابهة لما حصل عليه Wang من من منائج عند دراسته لطحلب S.dimorphus عند تعريضه لعنصـر الخارصـين، وكــلك إلـى مــاذكره العكَيلـي

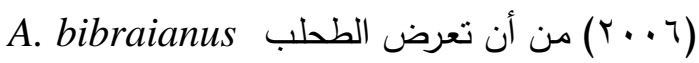

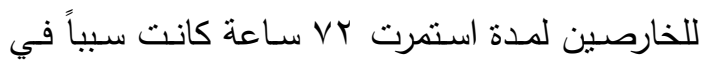
EC EC انخف
المحسوبة لطحلب Navicula incerta والطحلب

Chlorella والطسب Nitzshia closteirum saccharophila للرصاص. ولابد من الإثارة إلى أن درجة الاستجابة

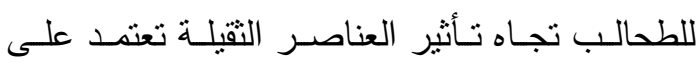

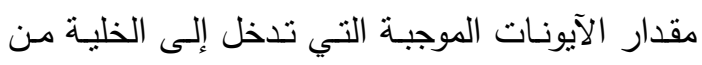

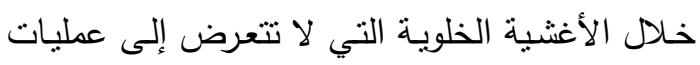

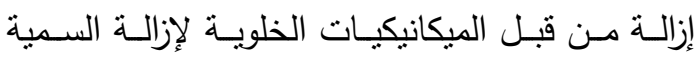
( Sauvant el al.1999) تشير النتائج في الجدول (1) إلى أن قيم

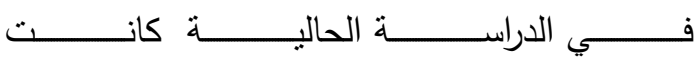

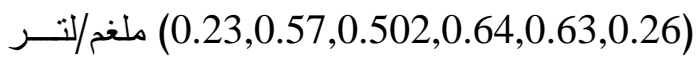
عند تعريض الطحلب إلى الكادميوم وهذا يتفق مع النع ما توصل إليه (1982) Rachlin et al. الذين أثنتوا انخفاض قيم EC Eم للـايتوم البحري Nitzschia closterinm Navicula incerta Chlorella saccharophila التعريض للكادميوم.

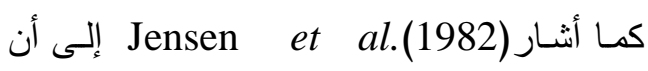

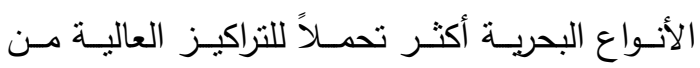

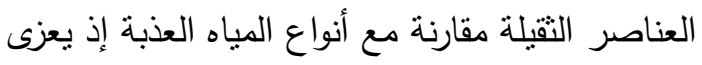
ذلك إلى الاختلاف في تركيب الجدار والتغيرات في لإني

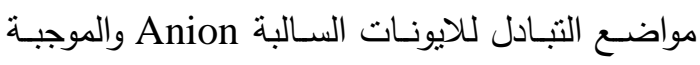

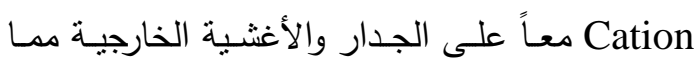

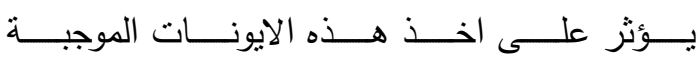
وهذا يفسر سبب اختلاف قيم $\left(\mathrm{Cu}^{+2}, \mathrm{Cd}^{+2}, \mathrm{~Pb}^{+2}\right)$ EC في الأنسواع البحريـة عنـه في أنسواع اليــاه

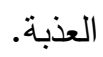

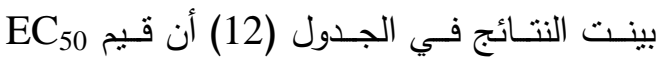
كانت منخفضة عند معاملة الطحلب بالنحاس (127. (0.608, 1.64, 0.25, 0.27, 1.22 
bibraianus

$$
\text { (ابن الهيثم) - جامعة بغداد. }
$$

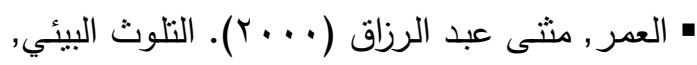

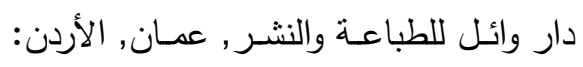

\section{.rTO}

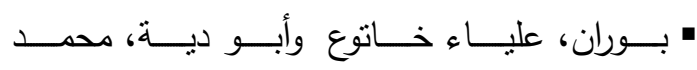

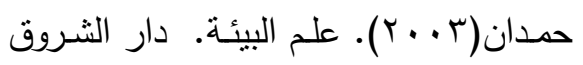

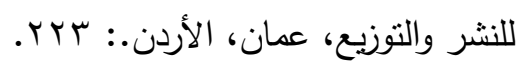

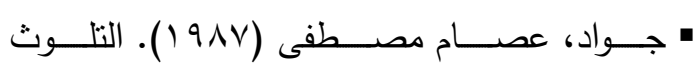

بالرصـاص والكادميوم وتأثيراتها الصـية.

ص بr-乏 في الندوة العلمية الثانية لكلية

التربية للبنات بموضوع تلوث البيئة المنعقدة

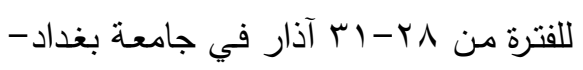

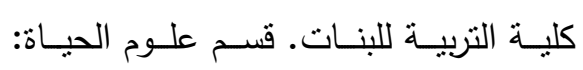

$$
. r .0
$$

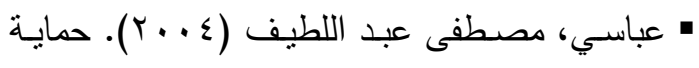
البيئة من التلوث- حماية الحياة، دار الوفاء

لدنيا الطباعة والنشر ، جامعة الاسكندرية:

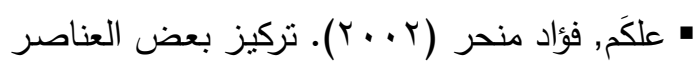

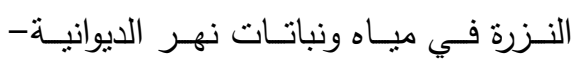

العـراق- مجلــة القادسـية. V| (1): 990

.19.

• قاسم، ثائر إبراهيم والسعدي، حسين علي ومحمد،

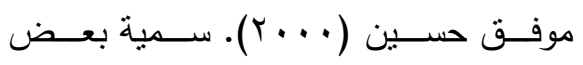

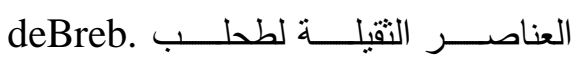

Scenedesmus quadricauda(Turp.)

في المزارع الثابتة. وقائع المؤتمر القطري

الأول في تلوث البئئة و أسـاليب حمايتها

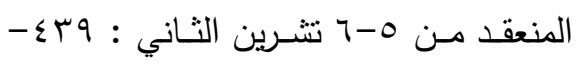

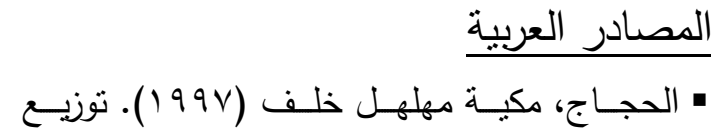

العناصر الثقبلة في مياه ورواسب قناتي

العشار والخندق المرتبطة بشط العرب وبيان

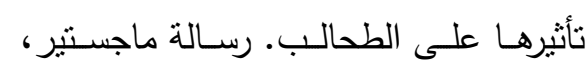

كلية العلوم- جامعة البصرة.

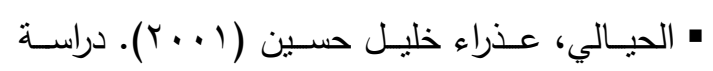

التأثير السمي لمعدني الكادميوم والرصاص (باص

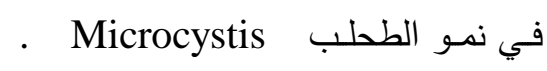

، رسالة ماجستنير aeruginosa kuetz.

$$
\text { كلية العلوم-جامعة بابل. }
$$

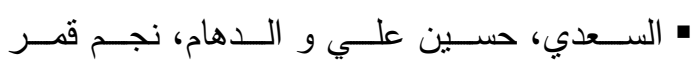

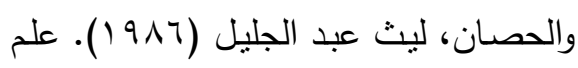

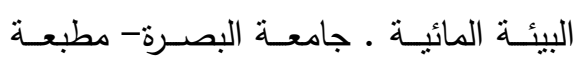

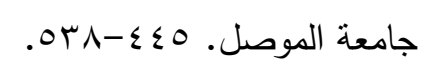

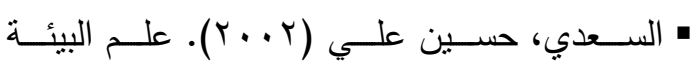

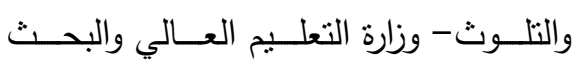

$$
\text { العلمي - جامعة بغداد. }
$$

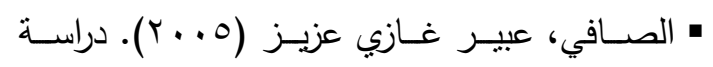

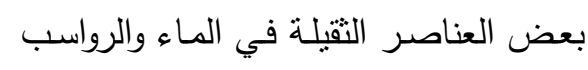

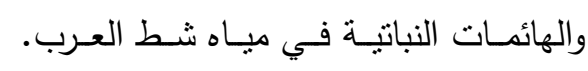

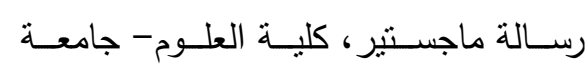

$$
\text { البصرة. - - مالة }
$$

- العادل، خالد محمد وعبد ، مولود كامل (9V9 (1)).

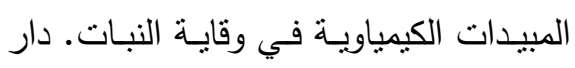

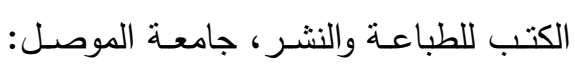

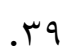

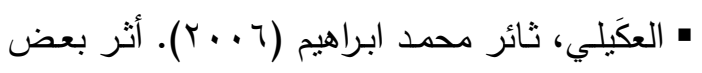

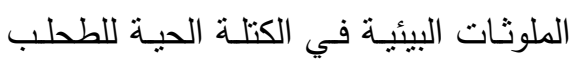

Ankistrodersmus 
A. (eds.) .metal section and contamination of siol. Lewis publisher.

- Harrison, G. I. and Marel, E. M. (1983). Antagonism between cadmium and iron in the marine diatom. Thalossiasira weissflogli. J. Phycol. 19: 495507.

- Jensen, T. E.; Rachlin, J. W.; Jani, V. and Warkentin, B. (1982). An Xray energy dispersive study of celluar compartmentalization of lead and zinc in Chlorella sacchrophila a (Chlorophata), Naviculla incerata and Nitzschia closterium (Bacillariophyta). Environmental and Experimental Botany, 22(3): 319-328.

- Kassim, T. I.; Al-Saadi, H. A. and Salman, N. A. (1999). Production of some phyto and zooplankton and their use as live food for fish larvea. Iraqi. J. Agricultural. Proc. $2^{\text {nd }}$ conf. Animal Product, Poultry and Fish. 4 (5): 188-201.

- Kessler, E. (1986). Limits of growth of five Chlorella species in the presence of toxic heavy metals. Arch. Hydrobiol. Suppl. 73(1): 123-128.

- Knaur, K.; Behra, R. and Sigg, L. (1997). Adsorption and uptake ofcopper by the green algae Scenedesmus subspicatus (Chlorophyta). J. Phycol., 33: 596-601.

- Martinez, M. R.; Chakraff, R. P. and Pantastico, J. B. (1975). Note on direct phytoplantkton counting technique using the

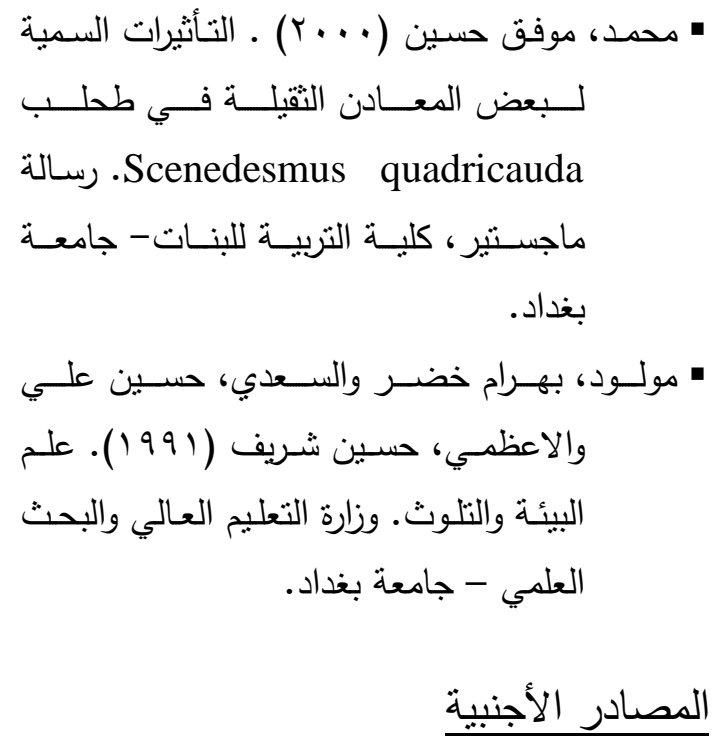

- Albergoni, V.; Piccinni, E. and Coppellotti, O. (1980). Response to heavy metals in organisms, excretion and accumulation of physiological and nonphysiological metals in Eugena gracilis. Comp. Biochem. Physiol. 67: 121-127.

- Barque, J. P.; Bourezgui, Y.; Chacun, H. and Bonaly, J. (1995). Growth responses of a chlorophyll. Us Euglena gracillis to selected concentration of cadmium and pentachlorophenol. Arch. Enviro. Contam. Toxicol., 28(1): 8-12.

- Chu, S. P. (1942). The influence of the mineral composition of the medium on the growth of phytoplanktonic algae. J. Ecol. 30: 284-325.

- Crompton, T. R. and Consultnt, A, G. (1998). Toxicant in the aqueous ecosystem. John wiley and sons.

- Forsetner, M. (1995). Land Contamination by metals: Global Scope and magnitude of problem, In: Allen, Huang, C. and Bower, 
concentration of the divalent cations $\mathrm{Cd}, \mathrm{Cu}, \mathrm{Pb}$, and $\mathrm{Zn}$, Symposium, Hemphill, D. D. (ed.)Unv. of Missori, Columbia, 72-81Pp.

- Rai, L. C.; Jonsen, T. E. and Rachlin, J. W. (1990). Amorphometric and $\mathrm{x}$-ray dispersive approach to monitoring $\mathrm{PH}$-altered cadmium toxicity in Anabaena flos-aeque. Arch. Environ. Cotam. Toxical., 19: 479-487.

- Reynolds, C. S. (1984). The ecology of fresh water phytoplankton." Cambridge univ. Press.

- Rijstenbil, J. W.; Sadee, A.; Van. Drie, J. and Wijnholds, J. A. (1994). Interaction of toxic trace metals and mechanism of ditoxification in planktonic diatom Ditylum brightwellii and Thalassiosira pseudonano. (FEMS) Microbiology Reviews 14: 387396.

- Saenz, M. E.; Accorinti, J. and Tortorelli, M. D. (1993). Toxicity of paraquat to green alga Scenedesmus acutus. J. Eviron. Sci. Health. 28(2): 193-204.

- Sauvant, M. P.; Pepin, D. and Piccinni, E. (1999) Tetralymena pyriformis: atool for toxicological studies. Review, chemosphere, 38 (7): 1631

- Sicko-Good, L.; Ladewski, P. and Lazinsky, D. (1986). Synergistic effect of nutrient and lead on quantitative of ultrastructure of Cyclotella (Bacillariophyceae). Arch. Environ. Contam. Toxicol., 15: 291-300.
Haemocytometer. Phil. Agric. 57: 1-12.

- Munda, I. M. and Hudnik, V. (1986). Growth response of Fucus vesiculosus to heavy metals singly and dual combinations as related to accumulation. Botan. Mar. 29: 401-412.

- Munda, I. M. and Hudnik, V. (1991). Trace metal content in some sea Weeds from the Northern Adriatic. Botan. Mar. 34: 241249.

- Nyholm, N. (1985). Response variable in algal growth inhibition test biomass or growth rate . Wat. Res. 19(3): 273-279.

- Patterson, G. (1983). Effect of heavy metals on fresh water chlorophyta . Ph. D. thesis, Durham. Univ., 212 Pp.

- Pistocchi, R.; Guerrini, F.; Balboni, V. and Boni, L. (1997). Copper toxicity and carbohydrate production in the micro algae Cylindrothica fusiformis and Gymnodinium Sp. Eur. J. Phycol., 32: 125-132.

- Rachlin, J. W. Warkentine, B. and Jensen, T. E. (1982). The growth response of Chorella saccharophila, Navicula incerta and Nitzschia closterium to selected concentration of cadmium. Bull. Torry. Bot. Club., 109: 129-135.

- Rachlin, J. W.; Warkentine, B. and Jensen, T. E. (1983). The response of marine diatom Nitschia losterium to selected 
- Vymazal, J. (1990). Toxicity and accumulation of lead with respect to algae and Cyanobacteria: Areview. Acta Hydrobiol. Hydrochem. , 18(5): 513-535.

- Wang, W. (1982). Analgal assay technique for aquatic toxicants. ISWS/RI-10 -82, 3Dep. Energy. Nat. Resour. 30.

- Wells, P. G. (1999). Aquatic toxicology . Concepts and practice. In press-General and applied toxicology. $2^{\text {nd }}$ ed.

- Wong, P. T. S. and Chan, Y. K. (1990). Zinc toxicity to fresh water algae . Toxic. Assess. 5(2): 167-177.
- Stauber, J. L. (1995). Toxicity testing using marine and fresh water Unicellular algae. Australasin J. Ecotoxicol. 1: 15- 24.

- Sunda, W.G. (1990). Trace metal interactions with marine phytoplankton . Biol. Oceano., 6: 411- 442.

- Tam, N. F Y. and Wang, Y. S. (1989). Waste water nutrients removal by Chlorella pyrenoidosa. Environ. Poll. 58: 19-34.

- Torres, M.; Goldberg, J. and Jensen, T. E. (1998). Heavy metals uptake by polyphosphate bodies in living and killed cells of Plectonema boryanum (Cyanophyeae).Microbios, 96:141-147. 


\title{
Effect of some heavy metal on absorption values of green alga Scenedesmus dimorphus
}

\section{Foad M. Alkam \\ Dunia B. Jad'an \\ Dept.of Biology-College of Education- University of Al-Qadisiya}

\begin{abstract}
$\underline{\text { Abstract }}$
The present study was concerned with the effect of some heavy metals (Lead, Cadmium, Copper, and Zinc) and their toxicity individually on the growth of green alga Scenedesmus dimorphus which belongs to the phylum of Chlorophyta .This was achieved depending on the absorption values to measure the living biomass of the alga,and then computing the growth average and doubling time when exposing the alga to these metals.

The effective median concentration $\mathrm{EC}_{50}$ of each of these four metals were also computed.The concentrations $(15,20,25,30) \mathrm{mg} / \mathrm{l}$ of lead were used. Results showed that exposing the alga to the concentration (30) $\mathrm{mg} / \mathrm{l}$ caused an acute decrease in growth. The other concentration $(15,20$, $25) \mathrm{mg} / \mathrm{l}$ also led to a gradual decrease in growth. Treating the alga with $(0.05,0.1,0.5,1) \mathrm{mg} / \mathrm{l}$ concentration of Cadmium the number of cells decreased in case of three concentration (0.05, $0.1,0.5) \mathrm{mg} / \mathrm{l}$. The decrease in growth was greater and clearer in case of the concentration (1)mg/l concentration Cadmium.As for Copper the concentrations $(0.5,1,1.5,2) \mathrm{mg} / \mathrm{l}$ and the concentration (2)mg/l had the greatest effect in deceasing growth. Results also showed that the concentration (3) $\mathrm{mg} / \mathrm{l}$ of zinc had the greatest effect in decreasing the growth on compared with the other concentration $(0.7,1,2,3) \mathrm{mg} / \mathrm{l}$. The toxic effect of cadmium proved greater than that of zinc copper, and lead in terms of the effective median concentration which indicated $(0.23,0.396$, $0.35,6.8) \mathrm{mg} / \mathrm{l}$ after treating the alga with lead, cadmium, copper, and zinc for (144) hours. Results were then analyzed statistically by using the variance analysis (ANOVA) and testing the difference between the treatments according to the Least Significant Difference (LSD)in $\mathrm{p}<0.05$.
\end{abstract}

